\title{
Organización espacial del sistema bancario dentro de la ciudad: estrategia territorial, accesibilidad y factores de localización
}

\section{Spatial organization of the banking system inside the city: territorial strategy, accessibility and factors of localization}

\author{
Carlos Félix Garrocho-Rangel* \\ Juan Campos-Alanís**
}

\begin{abstract}
In previous analysis carried out in Mexico on who are excluded from the banking and financial services, some key aspects related to the spatial organization of the banks have been left aside. Three topics are distinguishable: 1) the strategy of the location of branches; 2) the inequalities of access it generates; and 3) the factors of localization which determine it. Exploring, these three topics in a concrete city would allow understanding better the logic of the spatial behavior of the banking sector, drawing lessons and identifying the opportunities to design public policies that open more access opportunities to financial services for the population and enterprises Mexican. This is, indeed, what this work attempts, taking as study zone the Metropolitan Area of Toluca (MAT).
\end{abstract}

Keywords: intra-urban banking services; accessibility; location strategy; spatial analysis; banking process.

\section{Resumen}

En análisis previos realizados en nuestro país sobre quiénes están excluidos de los sistemas bancario y financiero, se han dejado de lado varios aspectos clave relacionados con la organización espacial de la banca. Destacan tres temas: 1) la estrategia de ubicación de las sucursales; 2) las desigualdades de acceso que genera; y 3) los factores de localización que la determinan. Explorar, estos tres temas en una ciudad concreta permitiría entender mejor la lógica del comportamiento espacial del sistema bancario, derivar lecciones e identificar oportunidades para diseñar políticas públicas que abran más oportunidades de acceso a servicios financieros a la población y a los negocios mexicanos. Esto es precisamente lo que se intenta en este trabajo, tomando como zona de estudio el Área Metropolitana de Toluca (Амт).

Palabras clave: servicios bancarios intraurbanos, accesibilidad, estrategia de ubicación, análisis espacial, desbancarización. 


\section{Introducción: desbancarización y exclusión financiera en el espacio intraurbano}

La intermediación financiera, mediante la banca comercial, es un servicio fundamental para el funcionamiento eficiente de la economía, y para que los beneficios de su crecimiento se difundan entre todos los integrantes de la sociedad. En México, la incapacidad del sistema financiero para cubrir a toda la población, así como a las micro y pequeñas empresas, ha generado la existencia de un grupo minoritario que dispone de servicios del sistema financiero (los bancarizados) y una mayoría que cuenta con esos servicios sólo de manera parcial o que no dispone de ellos (los desbancarizados) (Ruiz, 2004; вм 2005a, b; Rojas, 2006). ${ }^{1}$

En México el acceso a los servicios financieros es limitado, costoso y su nivel de penetración bajo: en el año 2006, en 74\% de los municipios -donde vivía $22 \%$ de la población nacional- no había sucursales bancarias, y $85 \%$ de los adultos que residían en ciudades nunca habían utilizado los servicios del sector financiero formal, lo cual es grave si se considera que nuestro país es predominantemente urbano. ${ }^{2}$ El bajo nivel de utilización del sector financiero formal en México hace que los desbancarizados enfrenten costos de transacción demasiado elevados en el pago de servicios públicos, envío de remesas y cobro de cheques (incluidos los de programas gubernamentales de combate a la pobreza, como Oportunidades); y que incurran en el pago de intereses muy elevados derivados de mecanismos de crédito alternativos (como casas de empeńo, prestamistas) y una muy baja o ausente obtención de réditos por ahorros o inversiones (por ejemplo, tandas, dinero guardado en casa, etc.) (вм, 2006).

Por tanto, ser desbancarizado (como individuo o como micro o pequeña empresa) afecta directamente el ingreso (y en consecuencia el nivel de vida), porque el dinero cuesta más caro, se limitan las oportunidades de negocio, no se reciben intereses por los ahorros y se requiere invertir más tiempo y energía para pagar las cuentas y cambiar cheques. ${ }^{3}$ Se ha estima-

\footnotetext{
${ }^{1}$ En los países desarrollados esta situación es a la inversa: la mayoría de la población está bancarizada (por ejemplo, en Estados Unidos 90\% cuenta con el servicio y 10\% no, TFRBC, 2001), pero en los países en desarrollo la situación es similar a la de México (Bм, 2005a). Cabe mencionar que entre los pocos datos sobre desbancarización a escala intraurbana para nuestro país, destaca el de la ciudad de México: 74\% de su población no tenía el servicio en 2003 (Ruiz, 2004).

${ }^{2}$ La escala intraurbana de la exclusión financiera es muy importante en México debido a su carácter predominantemente urbano: la proporción de población urbana, que era de $62.8 \%$ en 2005 , llegará a $67.8 \%$ en 2030 , lo que implica que en ese año alrededor de 82 millones de personas residirán en ciudades. Se estima que el total de la población del país llegará en 2030 a 120.9 millones (Conapo, 2009).

${ }^{3}$ En la ciudad de México, $80 \%$ de los desbancarizados que trabajan reciben su salario en forma de cheque (вм, 2005a).
} 
do, con gran precisión, que la falta de servicios bancarios puede costarle a un microempresario 68\% de su ingreso anual (Ruiz, 2004).

El fenómeno de desbancarización se debe a diversas barreras que impiden utilizar los servicios bancarios, y se pueden agrupar en dos grandes categorías: barreras de costo y barreras de localización (Ruiz, 2005; Connolly y Hajaj, 2001; Graves, 2003; Solo, 2008). ${ }^{4}$ La primera categoría se refiere, por ejemplo, a las comisiones que cobran los bancos por sus servicios (como la comisión anual por tarjetas de crédito, las diversas comisiones por apertura y mantenimiento de créditos hipotecarios, por utilizar cajeros automáticos) y a los requerimientos de saldos mínimos iniciales para abrir una cuenta o de saldos promedios mensuales mínimos para evitar recargos. La segunda categoría, las barreras de localización, se relaciona, principalmente, con las restricciones de acceso derivadas de la ubicación de los puntos de servicio (las sucursales). Las barreras de localización son muy importantes incluso a escala intraurbana: 30\% de los desbancarizados en la ciudad de México reportan que la localización de las sucursales es un factor clave que les impide el acceso al sistema bancario (вм, 2005a).

Datos como el anterior ilustran lo erróneo de la idea de la extinción de las sucursales bancarias, según la cual éstas desaparecerían como resultado de la amplia disponibilidad de cajeros automáticos y de nuevas tecnologías de la información (como transacciones por teléfono, banca electrónica por Internet) (Hirtle y Metli, 2004). Ésto, que en el fondo implicaba también la desaparición de la fricción de la distancia, simplemente no se cumplió: las sucursales bancarias siguen siendo un elemento clave para proveer servicios financieros en prácticamente todos los países del mundo, incluido México: ${ }^{5}$ mientras en enero de 2002 existían 6,511 sucursales bancarias en el país, en septiembre de 2008 habían llegado a 10,772 , lo que equivale a un crecimiento de $65.4 \%$ en poco más de seis años (CNBv, 2009).

A la combinación de las diferentes barreras que impone el sistema financiero para prevenir la utilización de los servicios bancarios, especialmente de los grupos sociales más pobres, se le ha dado en llamar exclusión financiera (CE, 2008; Connolly y Hajaj, 2001; Bernard et al., 2008; Leyshon y Thrift, 1995). Este fenómeno tiene profundas implicaciones de

\footnotetext{
${ }^{4}$ Aunque también se detectan problemas relacionados con la falta de confianza de los consumidores y problemas institucionales de los propios bancos, que afectan la calidad de sus servicios. Ver, por ejemplo, Rojas, 2006; вм, 2005a.

${ }_{5}^{5}$ Aunque es innegable que en diversos países del mundo se redujeron las sucursales bancarias a finales de la década de los noventa, especialmente en áreas de ingresos bajos (Reino Unido, Nueva Zelanda y Australia), la tendencia se revirtió desde el principio de este siglo. Incluso, en países como Estados Unidos o México las sucursales bancarias han crecido sistemáticamente desde hace décadas (Morrison y O'Brien, 2001: 303; AMB, 2009; CNBV, 2009).
} 
política pública, porque agudiza innecesariamente las diferencias en los niveles de ingreso y en las oportunidades de desarrollo entre grupos de población, regiones y áreas intraurbanas (Buckland y Gunther, 2005; Solo, 2008).

Sin embargo, salvo excepciones (вм, 2005a; Ruiz, 2004), se ha estudiado muy poco el acceso a los servicios bancarios en México a escala intraurbana, y cuando se ha hecho se consideran indicadores muy gruesos de disponibilidad del servicio (por ejemplo, sucursales por diez mil habitantes), unidades espaciales muy agregadas (municipios y delegaciones) y no se ha analizado en detalle el patrón locacional de las sucursales bancarias; a pesar de que se reconoce ampliamente la importancia de la variable espacial en el acceso a los servicios que prestan los bancos (BM, 2005a: xvii; Ruiz, 2004: 568).

En otras palabras, en análisis realizados en nuestro país, se han dejado de lado varios aspectos clave relacionados con la organización espacial del sistema bancario, que resultan fundamentales para avanzar en el entendimiento de la desbancarización y la exclusión financiera en el espacio intraurbano. Destacan tres aspectos: 1) la estrategia de ubicación de las sucursales bancarias; 2) los diferentes niveles de accesibilidad que genera; y 3) los factores de localización que la determinan. Explorar por lo menos estos temas en una ciudad concreta permitiría entender mejor la lógica del comportamiento espacial del sistema bancario, derivar lecciones e identificar oportunidades para diseñar políticas públicas que abran más oportunidades de acceso a servicios financieros a la población y los negocios desbancarizados de las ciudades mexicanas. Esto es lo que se intenta en este trabajo, tomando como zona de estudio el Área Metropolitana de Toluca (Амт).

Esta investigación se divide en seis secciones. En la primera se presentan los argumentos teóricos generales que explican el patrón de ubicación de las sucursales bancarias en el espacio intraurbano. En el segundo apartado se describe brevemente la zona de estudio y las fuentes de información, subrayando sus ventajas y limitaciones. En la tercera sección se examina el patrón espacial de las sucursales bancarias en el AMT, específicamente la evolución de la oferta y la demanda, la desigualdad espacial de la provisión de servicios, la estructura espacial del sistema de sucursales, la intensidad de su aglomeración y la colocalización de sucursales bancarias de diferentes firmas en competencia. En la cuarta sección se analizan las diferencias de accesibilidad a los servicios bancarios que se derivan del patrón de ubicación de las sucursales, utilizando un índice de accesibilidad espacial. Los resultados del análisis de accesibilidad se recuperan en la sección cinco para identificar los segmentos de la demanda que más afectan la localización de las sucursales (específicamente, la in- 
fluencia de dos variables clave: población y empleo). Por último, en el sexto apartado se sintetizan los hallazgos, se identifican las principales lecciones y se perfilan acciones de política pública orientadas a reducir las barreras de acceso a los servicios bancarios en ciudades mexicanas. El texto cierra con la bibliografía consultada.

\section{La teoría: ¿̨cómo se explica la localización intraurbana de las sucursales bancarias?}

\subsection{Principios generales}

La estrategia de ubicación de las sucursales bancarias, como puntos de oferta de servicios privados, en general siguen la misma lógica de localización de otras firmas (Jones y Simmons, 1990). Es decir, los bancos reconocen que la distribución espacial de su mercado (por ejemplo, sus clientes, sus sucursales y las sucursales de la competencia) no se distribuye de manera homogénea en el territorio, y que, por tanto, existen sitios estratégicos en la ciudad que ofrecen ventajas para sus sucursales (Birkin et al., 2002). El reto para los bancos es, entonces, identificar estos sitios para desplegar su estrategia locacional, cuyo objetivo es maximizar tres aspectos clave que están interrelacionados: 1) la accesibilidad de los clientes potenciales (su demanda); 2) la venta de servicios bancarios; y 3) las ganancias de la firma en su conjunto (Garrocho et al., 2002; Willer, 1990).

Sin embargo, identificar estos sitios estratégicos no es asunto sencillo, porque intervienen diversas variables que actúan en múltiples direcciones: lo atractivo del sitio (una plaza comercial de lujo es más atractiva que un barrio marginal), los costos de transporte (usualmente el centro de la ciudad o los subcentros de actividad son más accesibles que las zonas periféricas), la calidad de las vialidades (una gran avenida ofrece más ventajas de ubicación y visibilidad que una calle secundaria) o las percepciones diferenciadas de los clientes (la apreciación de la seguridad en ciertas zonas de la ciudad o lo atractivo que le resultan ciertos espacios intraurbanos a cada segmento del mercado), por mencionar algunos aspectos. Todo, en un contexto de cambios acelerados y permanentes (Garrocho, 2005, 2003).

\subsection{Patrones de localización de las firmas: ¿aglomeración o dispersión?}

Si bien los principios generales de la estrategia de ubicación de las firmas son conocidos, los resultados a menudo son divergentes. En términos básicos, podemos distinguir dos tipos de patrones de localización de las 
firmas: dispersos o aglomerados. La pregunta, entonces, se puede formular de la siguiente manera: si dos firmas compiten en un mismo espacio (por ejemplo, una misma ciudad), ¿por qué se ubican juntas o separadas en el territorio? De inicio, lo más natural sería pensar que las firmas se repartirían el territorio para lograr monopolios espaciales, como lo propone, a escala regional, la teoría de lugar central (Christaller, 1966). Sin embargo, en los espacios intraurbanos esto sólo ocurre por excepción para ciertas firmas (como tiendas de abarrotes o de conveniencia). Así, la alternativa sería suponer, como Hotelling (1929), que las firmas siguen una estrategia de aglomeración para maximizar la atracción de su demanda, pero esto tampoco se cumple sistemáticamente en la ciudad. Entonces, ¿por qué en el espacio intraurbano algunas firmas siguen un patrón de ubicación en un espacio aglomerado, formando clusters (por ejemplo, joyerías, refaccionarias de autos) y otras siguen un patrón espacialmente disperso (como farmacias, tiendas de abarrotes)? La explicación se puede articular a partir de tres conceptos básicos: 1) las economías de aglomeración (y los factores que las generan); 2) el grado de sustitución o complementariedad de los bienes o servicios que ofrecen las firmas (como la existencia de productos que son sustitutos imperfectos, perfectos o simplemente complementarios); y 3) los costos involucrados en los procesos de búsqueda y compra de bienes o servicios por parte del consumidor (O'Sullivan, 2007; Garrocho, 2008).

Antes de revisar la explicación de las firmas que se organizan espacialmente en forma de clusters (o racimos), vale la pena hablar brevemente de las firmas que no se aglomeran en el territorio, para contrastar los razonamientos y porque la explicación es más sencilla.

\subsection{Firmas que se dispersan: los monopolios espaciales}

Algunas firmas terciarias no forman clusters en el territorio porque ofrecen productos que son sustitutos perfectos $\mathrm{y}$, por tanto, su colocalización no genera ventajas en el marco de los procesos de búsqueda y compra de productos por parte del consumidor (como ahorros del consumidor en el proceso de búsqueda de un bien o servicio), ni otras economías de aglomeración (por ejemplo, intercambio de información que mejore significativamente el desempeño de la firma). En consecuencia, para alcanzar el nivel de ventas que les permita sobrevivir, las firmas se dividen el territorio para lograr monopolios espaciales. Es decir, siguen un comportamiento opuesto al cluster, que es extensivo y disperso, similar al que propone la teoría de lugar central (O’Sullivan, 2007).

Uno de los ejemplos más evidentes de este tipo de comportamiento espacial en México lo constituyen las tiendas de conveniencia (como Oxxo, 
tiendas de abarrotes). La plataforma de ventas de estas firmas son productos que son sustitutos perfectos, porque son industrializados y están estandarizados en sus especificaciones (cerveza, refrescos, botanas, pan de dulce de marca comercial, etc.) y se ofrecen al mismo precio en cualquier punto del territorio. Cuando las firmas ofrecen productos idénticos en sus especificaciones y en su precio (es decir, cuando son sustitutos perfectos), basan sus decisiones de localización en los conceptos clásicos de umbral y rango (de la teoría de lugar central), y no en las economias de aglomeración, que para esas firmas son inexistentes, ya que no obtienen ninguna ventaja de agruparse espacialmente y en cambio sí resentirían todas las desventajas de ubicarse juntas en el territorio: dividir su demanda, sus ventas y su ganancia.

Sin embargo, el comportamiento espacial de las tiendas de conveniencia es una excepción, porque la mayoría de las firmas comerciales y de servicios (como las sucursales bancarias) ofrecen una mezcla de productos que son sustitutos imperfectos y complementarios, y por tanto se organizan espacialmente en forma de clusters para facilitar y hacer más económico al consumidor su proceso de búsqueda y compra de productos, así como aprovechar otras importantes economías de aglomeración, como se explica en la siguiente sección.

\subsection{Firmas que se concentran en el espacio: fuerzas de aglomeración}

Diversas firmas distintas entre sí o similares, incluyendo muchas que están en competencia directa (como las sucursales bancarias), se agrupan en los espacios intraurbanos. ${ }^{6}$ Estas aglomeraciones de firmas las explica la economía urbana a partir de las economías de aglomeración (Maoh et al., 2005), que son fuerzas económicas (ahorros, menores costos, gastos no realizados) que actúan sobre las firmas, generándoles ciertas ventajas y beneficios que las incentivan a juntarse en el territorio. Por tanto, si la aglomeración espacial genera a las firmas ciertas ventajas que favorecen un desempeño superior al que tendrían si actuaran de manera aislada, las firmas tendrán un incentivo para aglomerarse. Es decir, las firmas dejarán de lado la idea de contar con mercados espaciales exclusivos (que se derivarían de repartir-

\footnotetext{
${ }^{6}$ Existen muy pocos ejemplos de análisis intraurbanos de patrones de ubicación de sucursales bancarias en la literatura internacional. A menudo se cita el famoso artículo de Avery (1991) que analiza la provisión de sucursales bancarias en ciudades, pero las trata como unidades agregadas, es decir, entendiendo las ciudades como puntos (adimensionales), no como áreas. Quizá ejemplos más pertinentes sean: Lord y Wright (1981) para Charlotte, Carolina del Norte; Chang et al. (1997) para Nueva York; Topçu (2001) para Estambul; Graves (2003) (para ciudades de Louisiana e Illinois); Caskey (1992) para Atlanta, Denver, San José, Nueva York y Washington); Medina y Núñez (2006), que realizan un estudio similar al de Caskey pero para Bogotá. Para México no se encontraron análisis de este tipo.
} 
se el territorio), ya que esto se verá más que compensado por lo que obtienen operando agrupadas en el espacio, debido a las economías de aglomeración (O’Sullivan, 2007).

Cuando estas economías (es decir, las ventajas que influyen positivamente en el desempeño de la firma, que les generan ahorros o más ventas, por ejemplo) son locales a una misma industria (firmas que producen o venden bienes o servicios similares o complementarios), se llaman economias de localización y producen fuerzas de atracción espacial (fuerzas centrípetas) entre firmas similares o complementarias. Algunos ejemplos de este tipo de cluster son las zonas especializadas en ciertos productos o servicios en determinadas partes de la ciudad (como áreas de venta de refacciones automotrices, vestidos de novia o electrodomésticos) o, incluso, la aglomeración de firmas competidoras en ciertas instalaciones comunes (como las llamadas plazas de computación o los centros joyeros, por mencionar algunas). En cambio, cuando estas economías (ventajas) afectan a diversas industrias y sectores reciben el nombre de economías de urbanización, las cuales reflejan no sólo que la presencia de firmas de una industria beneficia/atrae otras industrias, sino que las fuerzas de atracción (de firmas) están relacionadas con las características propias de la ciudad (o de ciertas partes de la ciudad), por ejemplo: la disponibilidad de infraestructura (como agua, electricidad, vialidades), de servicios especializados (hospitales, bancos, despachos de abogados y contables, hoteles o universidades) o de mano de obra especializada o abundante. Las economías de urbanización y de localización actúan de manera simultánea en las firmas, y una muestra clara de esto es la aglomeración de oficinas corporativas de numerosas y diversas empresas que se localizan en ciertas zonas de las grandes ciudades (Porter y Solvell, 1999).

Es importante mencionar dos aspectos: 1) que las economías de urbanización generan el desarrollo de grandes ciudades diversificadas, y junto con las economías de localización, producen clusters de firmas comerciales y de servicios; y 2) que ambos tipos de economías tienen raíces explicativas comunes, por lo que a menudo simplemente se les denomina a ambas economías de aglomeración (Parr, 2002). ${ }^{7}$

Los vinculos entre las firmas son la clave de las economías de aglomeración. Sin embargo, estos vínculos pueden ser de muy diversos tipos, es posible que tomen diferentes formas y que incluso a veces resulten difíci-

\footnotetext{
${ }^{7}$ No todas las aglomeraciones de firmas ocurren por las economías de aglomeración. Por ejemplo, se pueden generar clusters debido a ciertas características del entorno, como la legislación. En este caso podemos mencionar a Las Vegas o Atlantic City, que son aglomeraciones de firmas del sector turístico debido a que ahí está legalizado el juego; también son ejemplos de esto ciertas partes de la ciudad que aglomeran actividades comerciales y de servicios muy especiales -los llamados giros negros- por acuerdos explícitos (como normatividad sobre usos del suelo) o tácitos (concesiones políticas y/o corrupción) entre ciertos empresarios y autoridades.
} 
les de identificar, especialmente en el sector terciario orientado al consumidor. Debe subrayarse que las economías de aglomeración se han estudiado, sobre todo, para las firmas del sector manufacturero (Porter y Solvell, 1999), y cuando se incorporan al estudio del sector terciario, se consideran particularmente las firmas de servicios orientadas a la producción (Daniels, 1985; Chung y Kalnins, 2001; Keeble y Nachum, 2001). Son mucho menos comunes los estudios sobre economías de aglomeración que consideran a las firmas terciarias que ofrecen bienes y servicios al menudeo y que están orientadas al consumidor en espacios intraurbanos, pero en algunos de estos estudios se ha clasificado a las economías de aglomeración en dos grandes rubros: 1) las que influyen en la productividad (como flujos de información que difunden mejores prácticas) y 2) las que inciden en un aumento en la demanda (por ejemplo, reducción de los costos de búsqueda y compra del consumidor) (Chung y Kalnins, 2001). En este trabajo nos orientamos más a las segundas. Adicionalmente, podemos concluir esta sección diciendo que se conocen, de manera general, cuáles son los factores clave que generan economías de aglomeración en el sector terciario (O’Sullivan, 2007; Garrocho y Flores, 2009) (cuadro 1).

Si bien la experiencia intuitiva, derivada de la observación, parece indicarnos que las sucursales bancarias siguen un patrón aglomerado en las ciudades mexicanas, ¿es esto cierto? Y si así es, ¿cuál es la intensidad de su aglomeración?, ¿en qué parte de la ciudad se aglomeran y por qué?, ¿siguen una cierta dirección en el territorio? y, finalmente, ¿qué implicaciones tiene todo esto para la provisión de servicios bancarios en las ciudades? Justamente estas preguntas se exploran en las siguientes secciones de este trabajo. 


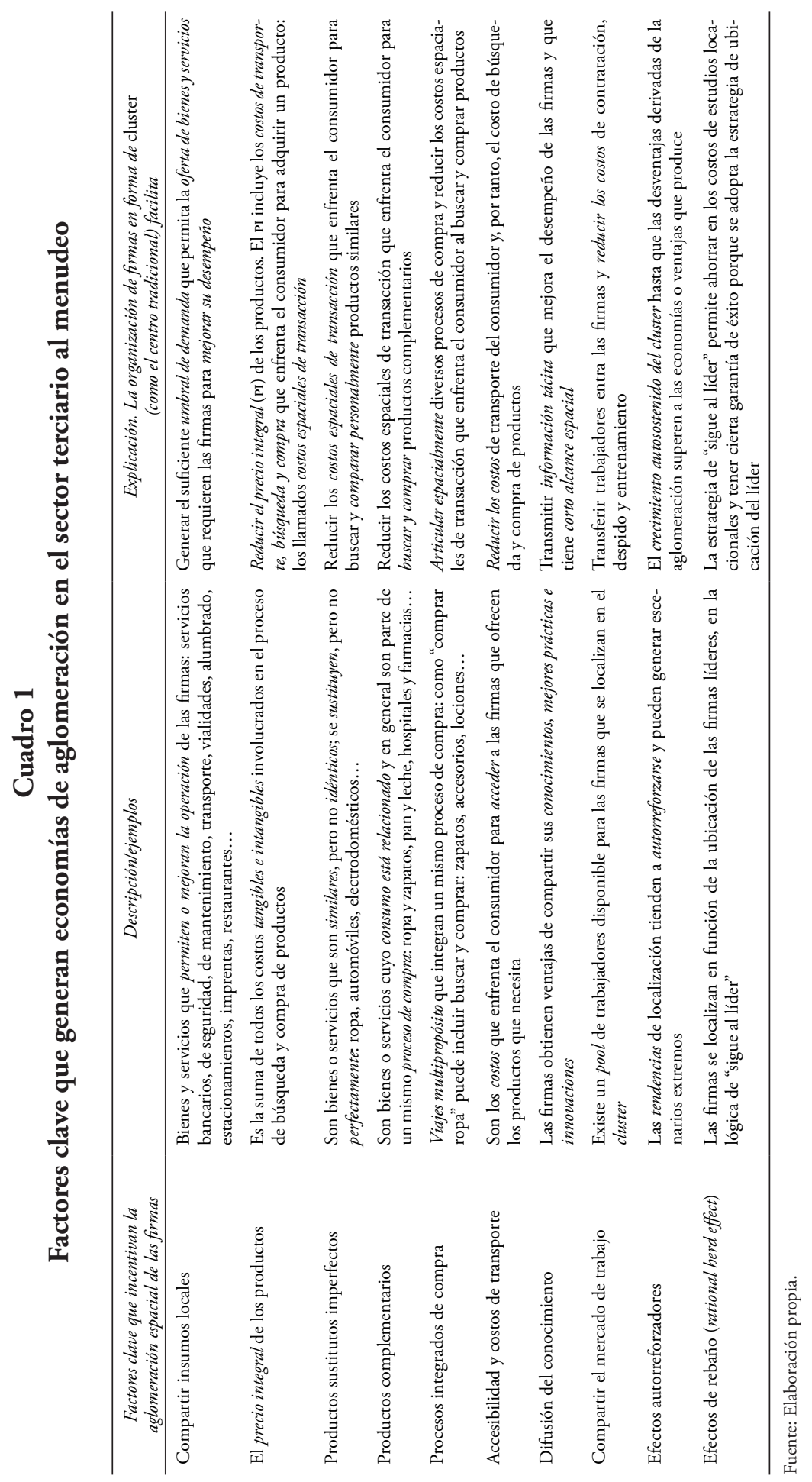




\section{Zona de estudio y fuentes de información}

\subsection{Zona de estudio}

El Área Metropolitana de Toluca (Амт) se localiza a media hora de la ciudad de México ( $40 \mathrm{~km}$ en dirección suroeste) y forma parte de la Zona Metropolitana del Valle de Toluca, integrada por 12 municipios del Estado de México. Tiene una superficie de $269.6 \mathrm{~km}^{2}$; su eje de longitud máxima este-oeste es de $31.6 \mathrm{~km}$ y el norte-sur es de $21.1 \mathrm{~km}$. Con 1.6 millones de habitantes es una de las cinco ciudades más grandes del país. El empleo formal, por su parte, ha tenido un comportamiento ascendente, aunque afectado por las recurrentes crisis económicas de México: en 1994 contaba con 157,284 empleos que llegaron a 267,603 en 2004, lo que indica que más allá de coyunturas económicas, Toluca es una de las ciudades más dinámicas del país y ha enfrentado un crecimiento metropolitano de gran escala. Esto ha modificado su estructura urbana y ha transformado a la ciudad monocéntrica de principios de la década de los ochenta, en una enorme área metropolitana policéntrica al inicio del siglo xXI (Garrocho y Campos, 2009a).

\subsection{Fuentes de información}

Para la elaboración de este trabajo se utilizó, fundamentalmente, información demográfica disponible en los Censos de Población y Vivienda 1990 y 2000; en los Conteos de Población 1995 y 2005; y en las proyecciones de población del Consejo Nacional de Población (Conapo) a escala de localidad. La información sobre empleo se tomó de los Censos Económicos 1994, 1999 y 2004. La desagregación espacial de la información que adoptamos es a escala de área geoestadística básica (Ageb). Como no existía un producto del Instituto Nacional de Estadística, Geografía e Informática (INEGI) que ofreciera información sobre empleo a este nivel de desagregación, se solicitó al INEGI los tabulados de información de los años mencionados para el Área Metropolitana de Toluca, así como la cartografía complementaria. Esta información se integró en un sistema de información geográfica (SIG) con el software ArcView 3.2 y en hojas de cálculo de Excel, para facilitar su análisis.

La información proporcionada por el INEGI se sometió a un proceso de normalización por dos razones fundamentales: la primera, porque el formato en que fue entregada dificultaba su integración al sig; y la segunda, porque la información tiene problemas de comparación entre los años considerados ya que, por ejemplo, los datos de los censos económicos de 1994 se elaboraron según la Clasificación Mexicana de Actividades y 
Productos (CMAP), mientras que los censos de 1999 y 2004 se elaboraron con el Sistema de Clasificación Industrial de América del Norte (sCiAN). Los procedimientos a los que se sometió la información permitieron comparar, desplegar y analizar la información sin problemas mayores.

Por lo que respecta a la información sobre las sucursales bancarias, se utilizaron directorios telefónicos para los años de estudio y se complementó con levantamiento en campo (como localización y número de cajas disponibles en cada sucursal), que se llevó a cabo durante los últimos dos meses de 2008 y los primeros meses de 2009. La localización de las sucursales bancarias se georreferenció con instrumentos de GPs que luego se integró al sig. Adicionalmente, se utilizaron fotos aéreas como fuentes cartográficas complementarias y diversas metodologías de tratamiento de la información disponibles y probadas desde hace ańos en el Laboratorio de Análisis Socioespacial de El Colegio Mexiquense, para garantizar la comparación entre Ageb de diferentes años.

\section{Patrón espacial: desigualdad, estructura y aglomeración}

\subsection{Evolución de la oferta y la demanda de servicios bancarios}

Entre 1990 y 2005, el área metropolitana de Toluca (АMT) registró una tasa de crecimiento de población de $4.49 \%$, una de las más aceleradas del país, con lo que su población pasó de 546 mil habitantes a poco más de un millón $(1,056,856)$, en el periodo de referencia. Esto equivale a un crecimiento de $93 \%$ de su población en tan sólo 15 ańos. El empleo formal también creció de forma acelerada: registró una tasa de crecimiento medio anual (тсмА) de $9.14 \%$ durante la segunda mitad de la década de los noventa, lo que significó un incremento de poco más de $86 \mathrm{mil}$ nuevas plazas en la ciudad entre 1994 y 1999 (pasó de 157,284 empleos a poco más de $243 \mathrm{mil}$ ). Para el siguiente lustro las cosas cambiaron en el país y en la ciudad. Debido a las crisis económicas, el crecimiento del empleo formal cayó dramáticamente, ya que entre 1999 y 2004 sólo se generaron 24 mil nuevos empleos, lo que representó una TCMA de 1.9\%, cifra casi ocho veces menor que la registrada apenas cinco años antes, pero superior al promedio nacional. ${ }^{8}$

Dado que la superficie de la ciudad creció de manera más lenta que la población y el empleo (pasó de $204.5 \mathrm{~km}^{2}$ a 269.6), la densidad de la población y el empleo se incrementó notablemente. La primera pasó de 2,674 personas por $\mathrm{km}^{2}$ en 1990 a 3,920 en 2005, y la segunda de 712

\footnotetext{
${ }^{8}$ En México los años de levantamiento de los censos de población y de los censos económicos no coinciden (están desplazados un ańo), por eso la diferencia de un año de los periodos de análisis.
} 
por $\mathrm{km}^{2}$ en 1994 a 902 en 2004. La expansión física de la ciudad y la redensificación de la población y el empleo modificaron la estructura de la ciudad, que pasó de un modelo monocéntrico a uno policéntrico (Garrocho y Campos, 2009a, b).

El dinamismo del AMT se refleja en el crecimiento de las sucursales bancarias en la ciudad. Mientras en 1990 existían 32 sucursales, en 2009 habían llegado a 109. Es decir, se triplicaron en poco menos de dos décadas, y la densidad de sucursales en la ciudad pasó de 0.16 en 1990 a 0.40 por $\mathrm{km}^{2}$ al final del periodo. La relación entre la oferta y la demanda de servicios bancarios también cambió de manera importante en los últimos años. En 1990 había 0.59 sucursales por cada diez mil habitantes, y en 2009 llegó a 0.94. Una tendencia similar ocurrió con la relación entre sucursales por cada diez mil empleos, que pasó de 2.7 en 1994 a 3.71 en 2009 ?

Las diferencias en la velocidad de crecimiento entre la oferta (sucursales bancarias) y la demanda (población y empleo) en el AMT muestran que la primera ha sido mucho más dinámica que la segunda. Sin embargo, se debe mencionar que en este periodo el modelo de las sucursales bancarias en México cambió drásticamente. Mientras al inicio del periodo diversas sucursales eran de gran tamaño (hasta 15 cajas en una sola sucursal), en 2009 había microsucursales hasta con sólo una caja, que eran impensables 20 años atrás.

Así, los elementos considerados hasta el momento (crecimiento físico de la ciudad, incremento acelerado de la población y el empleo, nueva estructura policéntrica de la ciudad, dinamismo de las sucursales bancarias y aparición de sucursales de menor escala) sugieren, como hipótesis, que las sucursales bancarias debieron cambiar su patrón de localización en el AMT. ¿Es esto cierto?, y si lo es, ¿el nuevo patrón de ubicación privilegió (o no) ciertas áreas de la ciudad y cuáles fueron? Estas preguntas se exploran a continuación.

\subsection{Desigualdad espacial en la provisión de servicios bancarios}

La provisión de sucursales bancarias en el AMT es altamente desigual en el territorio, aunque la tendencia es hacia una ligera reducción. En 1990 las 32 sucursales bancarias se concentraban en sólo 13 Ageb (de un total

\footnotetext{
${ }^{9}$ La población del AMT se calculó para 2009 a partir de las proyecciones municipales del Conapo (http://www.conapo.gob.mx/00cifras/proy/municipales.xls). Por su parte, el empleo se proyectó para 2009 con la tasa de crecimiento registrada de 1999 a 2004, lo que significa una estimación relativamente optimista, dada la tendencia histórica de crecimiento del empleo en el AMT. Por tanto, la relación entre oferta y demanda en 2009 es una aproximación, que si bien no es exacta, sí muestra una tendencia que es suficiente para los propósitos de esta sección del trabajo: mostrar que las sucursales bancarias han crecido más rápido que la población y el empleo.
} 
de 210) que equivalían a 5\% de la superficie de la ciudad, donde residía $9.2 \%$ de la población del AMT, pero se localizaba $24.9 \%$ del empleo. En 2005 el total de sucursales se localizaron en 46 Ageb (de un total de 345) que equivalían a $13.3 \%$ de la superficie urbana, donde se ubicaba $14.8 \%$ de la población, pero $50 \%$ del empleo. Al parecer, la expansión de sucursales bancarias en la ciudad se relaciona más con la presencia de empleo que con la presencia de población. Sin embargo, un indicador más fino, como el índice de Gini (IG), puede dar más luz sobre esto.

En 1990 el IG ${ }^{10}$ de las sucursales respecto a la población era de 0.91 , lo que indica una enorme desigualdad en la provisión de servicios bancarios en la ciudad. Para 2005, sin embargo, el IG se reduce ligeramente a 0.85 , lo que indica que se mantiene el patrón de alta desigualdad, pero con una tendencia decreciente. No obstante, si sólo se considera a la población ocupada de mayores ingresos que registra el censo (la que tiene ingresos de más de cinco salarios mínimos), el IG en 2000 baja a 0.74 , que es mucho menos desigual que cuando se considera la población total. ${ }^{11}$

Ahora bien, si se sustituyen las variables de población por las de empleo, los valores del IG muestran un patrón menos desigual en la provisión del servicio: 0.76 en 1994 y 0.59 en 2004. Adicionalmente, los sectores del empleo que muestran menores IG en 2004 corresponden a Otros servicios excepto actividades de gobierno (0.73 en 1990 contra 0.59 en 2005) y Actividades de gobierno (0.71 en 1990 contra 0.64 en 2005). Los valores de los IG sugieren, entonces, que las sucursales bancarias en el AMT siguen tanto al empleo como a la población de mayores ingresos, en un entorno de alta desigualdad en la distribución del servicio. Esto coincide, en cierta manera, con lo que reportan algunos estudios recientes para la ciudad de México (Ruiz, 2004; BM, 2005a; 2005b).

\subsection{La estructura policéntrica de los servicios bancarios}

En términos espaciales, el centro tradicional de negocios de la ciudad (CTN) sigue jugando un papel preponderante como sitio de localización de sucursales bancarias en el AMT, pero su importancia tiende a declinar. Mientras en 1990 dos de cada tres sucursales bancarias en la ciudad se localizaban en el CTN, en 2009 su concentración se redujo a 37.6\%. Por su parte, los demás subcentros de empleo del AMT que no registraban ninguna sucursal bancaria en 1990, tuvieron $14.7 \%$ de las sucursales en

\footnotetext{
${ }^{10}$ Los valores del índice de Gini tienen un rango de variación que va de 1.0 (máxima desigualdad) a 0.0 (mínima desigualdad).

${ }^{11}$ El censo de 2000 sólo registra la población ocupada por niveles de ingreso, aunque de manera muy gruesa: el estrato de población ocupada con mayor ingreso que registra es el que gana más de cinco salarios mínimos. Por su parte, el Conteo de Población de 2005 no incluye este dato sobre el ingreso de la población.
} 
2009. ${ }^{12}$ Esto indica que si bien los subcentros de empleo del AMT van ganando presencia de sucursales bancarias, todavía están rezagados, en este aspecto, del CTN. Además cabe subrayar que alrededor de la mitad de las sucursales bancarias de la ciudad se localizan fuera del CTN y de los principales subcentros de empleo, lo que sugiere que los bancos han adoptado una estrategia de ubicación más dispersa que en los años ochenta, orientada, seguramente, a lograr una mayor cercanía con la demanda que se ha extendido en la ciudad.

Los cambios en la distribución espacial del sistema bancario entre 1990 y 2009 son evidentes (mapa I a y b). En 1990 la estructura espacial de las sucursales a escala metropolitana tendía a ser monocéntrica, concentrada en una zona llamada Gran Toluca Centro (que incluye el CTN, el corredor Tollocan, sobre una de las vialidades más importantes de la ciudad, y una zona llamada Tablajeros, localizada en la salida a la ciudad de México; el Gran Toluca Centro se analiza en detalle en Garrocho y Campos, 2009a, b). Fuera del Gran Toluca Centro sólo se distinguían tres zonas que registraban sucursales bancarias (con sólo una sucursal en cada una de ellas): Metepec (al sur de la ciudad, donde se ubica Plaza de las Américas, entonces la única gran plaza comercial del АMT), Lerma (al este, en la salida a la ciudad de México, donde se localiza una importante zona industrial) y Zinacantepec (al oeste de la ciudad, hacia donde comenzaba a crecer el AMT en los ochenta y noventa).

En 2009 el paisaje del mercado es distinto: la demanda (población y empleo) se expande en el territorio y las sucursales bancarias también incrementan su presencia en diferentes partes de la ciudad, sobre todo hacia el norte, sur y este del AMT, que es donde se ha acelerado más el crecimiento del empleo y de la población durante los últimos 15 años. Así, la estructura bancaria en el espacio intraurbano deja de ser monocéntrica y se distinguen nuevas e importantes concentraciones bancarias que rompen las fronteras del Gran Toluca Centro y escapan a su fuerza gravitatoria, sobre todo en Metepec (al sur), en particular en la zona donde se localiza la plaza comercial más importante de la ciudad (Galerías Metepec); al este, en Lerma, sobre todo en la zona de la plaza comercial Sendero, en el centro tradicional de Lerma, en la zona industrial y en la plaza comercial Outlets Lerma (mapa Ib); en la zona del Aeropuerto Internacional (al norte del AMT); y sobre las vialidades que conectan el CTN con Lerma y con la zona del aeropuerto. Este cambio en el patrón de ubicación de las sucursales bancarias hace que el centroide geográfico ponderado de su distribución se mueva $2.7 \mathrm{~km}$ al este entre 1990 y 2009,

\footnotetext{
${ }^{12}$ A principios de los noventa el AMT tenía cinco grandes concentraciones de empleo (el CTN y cuatro subcentros emergentes) y ocho en 2004 (el cTN y siete subcentros emergentes) (Garrocho y Campos, 2009a, b).
} 


\section{Mapa I \\ AMT: Bancos instalados por Ageb, 1990-2009}

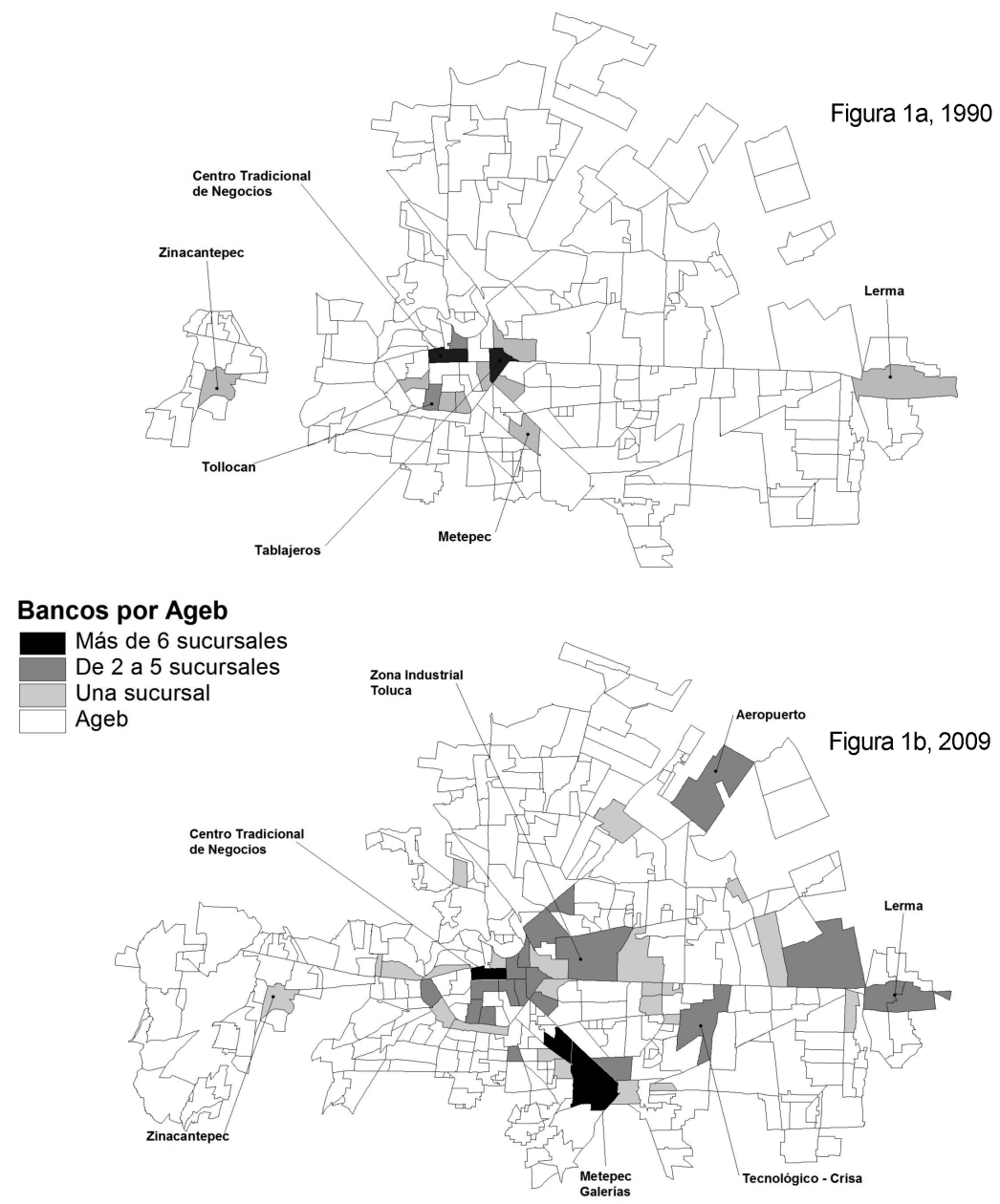

Fuente: Elaboración propia.

reflejando la expansión del sistema bancario (y de la ciudad en general) hacia las zonas estratégicas mencionadas (mapa II). ${ }^{13}$

Como se puede observar, el patrón de ubicación de las sucursales bancarias se ha descentralizado y pasó de ser monocéntrico en 1990 a policéntrico en 2009. Sin embargo, la simple observación no es suficien-

${ }^{13}$ Es el centroide geográfico de las sucursales bancarias, ponderado por el número de cajas disponibles en cada sucursal, que es una medida del tamańo de la sucursal. La manera de calcular este indicador, y otros que se presentan más adelante, se puede ver en Ebdon (1991) y Lee y Wong (2001). Ambos libros son muy amigables. 


\section{Mapa II}

AMT: centroides ponderados de las sucursales bancarias, población total y empleo total, 1990-2009

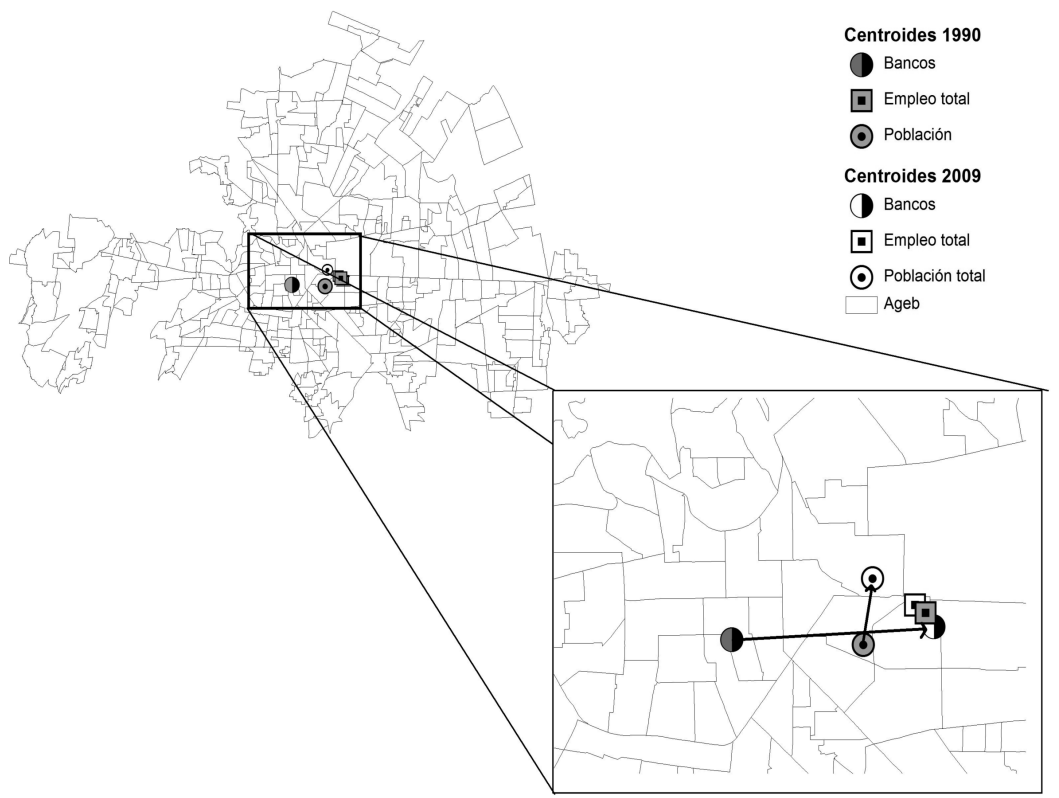

Fuente: Elaboración propia.

te. Se requiere un indicador de estadística espacial más fino que el centroide geográfico, que estime con mayor precisión la concentración o dispersión del patrón locacional de sucursales bancarias. Esto es lo que se hace en la siguiente sección, con el apoyo de tres indicadores de estadística espacial: la distancia estándar, la desviación estándar elíptica y el índice del vecino más cercano.

\subsection{Dispersión, orientación y patrón espacial}

\subsubsection{Dispersión y orientación espacial de las sucursales bancarias}

El indicador de estadística espacial más utilizado para estimar la dispersión de puntos alrededor del centroide geográfico de una muestra es la distancia estándar (DE), que equivale a la desviación estándar de la estadística convencional (Myint, 2008). En 1990 la DE tenía un valor de $3.2 \mathrm{~km}$ e incluía $94 \%$ de las sucursales del AMT, lo que refleja lo compacto y monocéntrico de la distribución espacial de las sucursales bancarias en la ciudad. En 2009, la DE se amplió a $5.1 \mathrm{~km}$, lo que indica una mayor 


\section{Mapa III \\ AMT: distancia estándar y desviación estándar elíptica de las sucursales bancarias, 1990-2009}

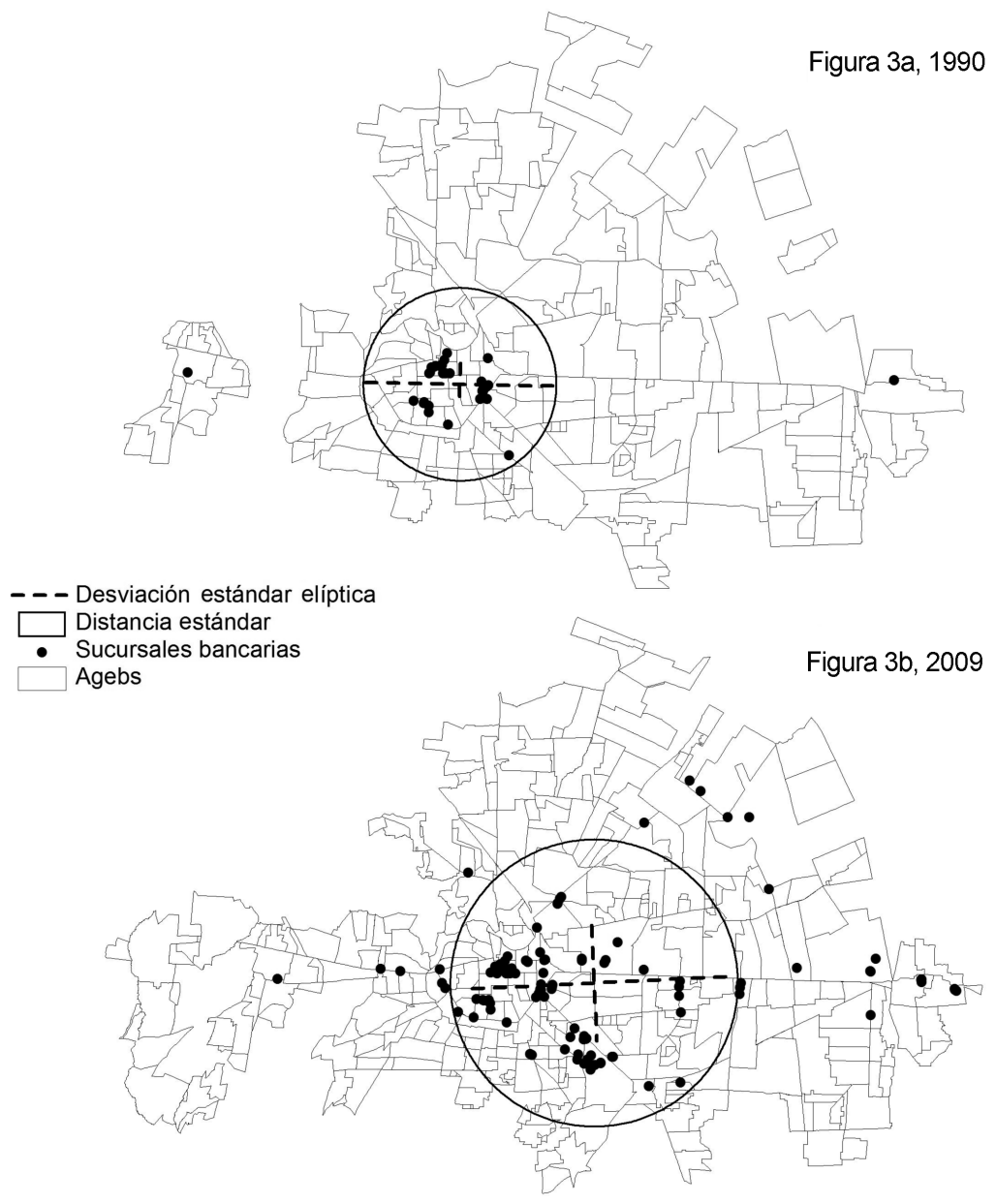

Fuente: Elaboración propia.

dispersión y cobertura espacial del sistema de sucursales bancarias en la ciudad que registró, también, una expansión importante en el periodo de estudio (tanto física, como de población y empleo). Esta mayor dispersión de las sucursales bancarias se confirma por el hecho de que en 2009 el porcentaje de sucursales incluidas en la DE bajó a 78\% (mapa III a y b).

Por su parte, la orientación espacial de una distribución de puntos se puede estimar mediante la desviación estándar elíptica (DEE), medida que sintetiza el comportamiento espacial de los puntos de acuerdo con sus patrones de máxima y mínima dispersión en el territorio. El eje más 
largo de la elipse corre en la misma dirección del eje de máxima dispersión espacial de la muestra de puntos, y el eje más corto en la dirección del patrón de mínima dispersión. Tanto en 1990 como en 2005, la DEE muestra que el patrón de sucursales bancarias en el AMT seguía una orientación este-oeste (el eje más largo de la elipse), lo que se explica porqué ésta ha sido la dirección predominante del crecimiento del AMT y porqué en esta dirección corren la gran mayoría de las vialidades más importantes de la ciudad (en dirección a la salida a la ciudad de México). Adicionalmente, es claro que ambos ejes de la DEE incrementan su longitud en el tiempo: el eje mayor pasa de $6.3 \mathrm{~km}$ en 1990 a 9.5 en 2009, y el eje menor aumenta de $1.5 \mathrm{~km}$ en 1990 a $4.2 \mathrm{~km}$ en 2009, lo que refleja la acelerada expansión territorial del sistema de sucursales bancarias en la ciudad, derivada del dinamismo físico, demográfico y económico del AMT (mapa III a y b).

\subsubsection{Patrón espacial de las sucursales bancarias: ¿aglomerado, disperso o aleatorio?}

Quizá la técnica más utilizada para analizar patrones espaciales de puntos en el territorio es la del vecino más cercano. Esta técnica la desarrollaron los biólogos ecologistas Clark y Evans en 1954, y desde entonces se ha aplicado en numerosos estudios académicos provenientes de diversas disciplinas (Haining, 1993). La técnica del vecino más cercano implica, justamente, la medición de la distancia media entre todos los puntos considerados (como sucursales bancarias) y el vecino más cercano a cada uno de ellos. La distancia media resultante se puede comparar con distancias medias teóricas, para identificar tres tipos básicos de patrones espaciales: aleatorios, dispersos (pero con cierta regularidad) y aglomerados (que forman clusters o racimos) (Ebdon, 1991).

El índice del vecino más cercano es, simplemente, la distancia media promedio al vecino más cercano observada, dividida entre la distancia promedio al vecino más cercano esperada para un patrón espacial aleatorio (Ebdon, 1991):

$$
\mathrm{R}=\mathrm{d}_{o} / \mathrm{d}_{e}
$$

Donde $R$ es el índice del vecino más cercano, $d_{o}$ es la distancia media promedio al vecino más cercano observada $y d_{e}$ es la distancia promedio al vecino más cercano esperada para un patrón espacial aleatorio. A su vez:

$$
\mathrm{d}_{e}=1 /(2 \sqrt{p})
$$


Donde $\mathrm{d}_{e}$ es la distancia promedio al vecino más cercano esperada para un patrón espacial aleatorio y $p$ es la densidad de puntos en el territorio (el número de puntos dividido entre el área). Esto explica que el rango de variación del índice del vecino más cercano esté delimitado por un valor mínimo de 0.0 (que corresponde a un patrón espacial de máxima aglomeración: donde la distancia al vecino más cercano para todos los puntos es cero) y por un valor máximo de 2.15 (que indica un patrón espacial de máxima dispersión: un patrón disperso y hexagonalmente regular como el derivado de la teoría de lugar central). En consecuencia, el índice para los patrones espaciales aleatorios tendrá un valor de 1.0 (cuando la distancia promedio al vecino más cercano observada sea igual a la esperada, ver ecuación 1). ${ }^{14}$

Resultados. En 1990 el índice del vecino más cercano para las sucursales bancarias del AMT era de 0.33 , lo que indica un patrón espacial muy concentrado, que funciona en forma de clusters (estadísticamente significativo con un nivel de confianza de 95\%). Esto se deriva de que la distancia promedio observada de cada sucursal bancaria a la sucursal más cercana es de $840 \mathrm{~m}$. Sólo tres sucursales ( $9 \%$ del total) se localizaban a más de $840 \mathrm{~m}$ de otra sucursal bancaria. En 2009, el índice del vecino más cercano se reduce y toma un valor de 0.22 , lo que indica un patrón de localización cuya tendencia a funcionar en clusters es mayor que en 1990. Es interesante observar, además, que la distancia promedio observada al vecino más cercano se reduce notablemente y es de apenas $360 \mathrm{~m}$, a pesar de que la ciudad se expandió en más de $65 \mathrm{~km}$ cuadrados en el periodo. Así, en 2009 (con casi tres veces más sucursales bancarias que en 1990), sólo 13 sucursales (12\% del total) se localizaban a más de $360 \mathrm{~m}$ de otra, lo que también da una medida del grado de aglomeración espacial de las sucursales bancarias.

El análisis se puede llevar más allá si se representa cartográficamente el valor de la distancia esperada, si las sucursales bancarias siguieran un patrón de máxima dispersión (el sombreado gris claro en el mapa iv a y b). Como se puede observar, en 1990 sólo dos sucursales bancarias, localizadas en los extremos oeste-este de la ciudad (la del oeste está en Zinacantepec y la del este en Lerma), no funcionan como cluster (lo que equivale a $6 \%$ del total de sucursales de la ciudad; mapa Iva). El resto se aglomera en el municipio de Toluca, manteniendo una distancia con sus vecinos más cercanos mucho menor a la esperada (representada en el mapa con color gris claro). Incluso, si la distancia esperada se divide entre dos (el sombreado gris oscuro en el mapa rva), todas las sucursales (con ex-

${ }^{14}$ La demostración matemática del índice del vecino más cercano se puede ver en detalle en Clark y Evans (1954). 


\section{Mapa IV \\ AMT: clusters de sucursales bancarias según la distancia esperada del vecino más cercano, 1990-2009}
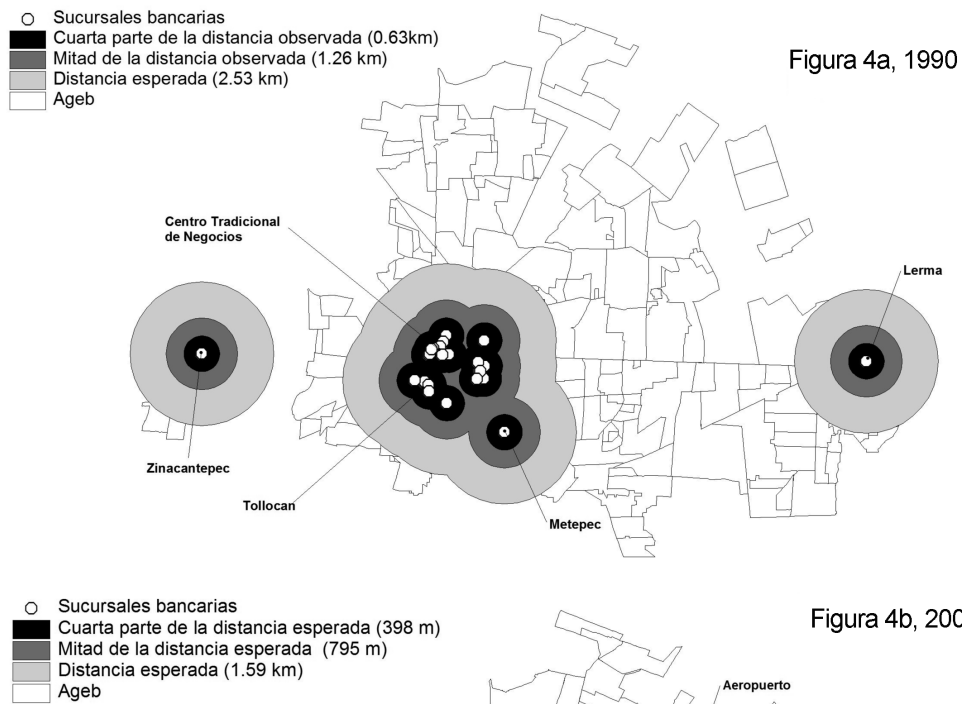
Ageb

Figura 4b, 2009
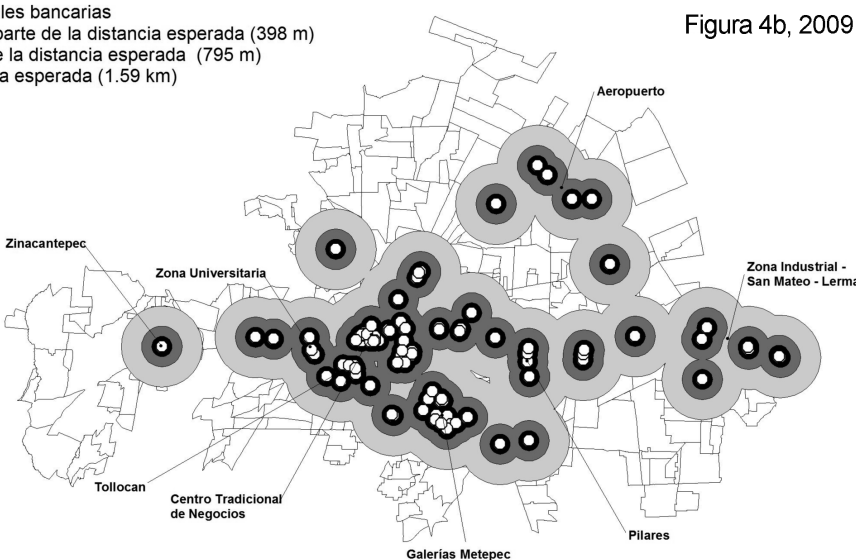

Fuente: Elaboración propia.

cepción de las dos mencionadas) siguen mostrando un patrón altamente aglomerado. El patrón espacial de las sucursales bancarias es tan aglomerado en 1990, que aun si la distancia esperada se divide entre cuatro (el sombreado negro en el mapa rva), sólo una sucursal bancaria adicional, localizada en Metepec, quedaría fuera del cluster central, lo que además confirma la estructura monocéntrica del sistema bancario de la ciudad.

Para 2009, a pesar de la expansión de la ciudad y del incremento de sucursales bancarias, sólo una sucursal muestra una localización no integrada a algún cluster (la que se ubica en Zinacantepec, que equivale a menos de $1 \%$ del total de sucursales). Todas las demás, 108 sucursales o 
99.1\% del total, registran una localización aglomerada, porque la distancia de cada sucursal a la otra más cercana es menor a la distancia esperada (la distancia esperada, si el patrón fuera aleatorio se representa con el sombreado gris claro en el mapa Ivb). Si la distancia esperada se divide entre dos (sombreado gris oscuro en el mapa rvb), sólo cinco sucursales (incluida la de Zinacantepec) registrarían una ubicación aislada de algún cluster (es decir, apenas 4.6\% del total de sucursales); y aun si se dividiera entre cuatro, sólo 10 sucursales $(9.2 \%$ del total) mostrarían un funcionamiento no aglomerado. La representación cartográfica de la distancia esperada dividida entre cuatro permite, además, apreciar los principales clusters bancarios en la ciudad en 2009 (mapa Ivb): el del cTN (32 sucursales), el de Tollocan (9), el de Galerías Metepec (20), el de la Zona Industrial de Lerma (6) y el de Pilares (4 sucursales), entre otros, así como confirmar la hipótesis de que la estructura espacial de las sucursales bancarias en la ciudad pasó de ser monocéntrica en 1990 a policéntrica en 2009 (mapa Iv a y b).

Los valores de un indicador de estadística espacial, como el índice del vecino más cercano, confirman las conclusiones derivadas de la observación de los datos, pero además evidencian con toda claridad que las sucursales bancarias funcionan en el territorio en forma de clusters. En otras palabras: en la gran mayoría de los casos, donde se localiza una sucursal bancaria se va a colocalizar otra sucursal. Esto se explica porque seguramente obtienen ventajas, economías de localización, que desconocemos en detalle, pero que se deben relacionar, entre otras, con reducir los costos de búsqueda y adquisición de servicios bancarios de los clientes (cuadro 1). Sin embargo, en la circunstancia en que las sucursales bancarias funcionan como clusters: ¿todas las firmas se atraen espacialmente de igual manera?, o acaso, ¿̇algunas firmas se atraen más que otras, unas se repelen y algunas más son indiferentes a la localización de la competencia? Estas preguntas se exploran en la siguiente sección.

\subsection{Colocalización de sucursales bancarias: ¿atracción, rechazo o indiferencia entre firmas?}

El indicador del vecino más cercano permite sintetizar el patrón espacial de un conjunto de firmas en el territorio, pero no es útil para examinar la asociación entre los patrones espaciales de dos firmas que compiten en el mismo territorio (en la misma ciudad, como el AMT). Sin embargo, la literatura informa un indicador, derivado del índice del vecino más cercano, que permite, justamente, medir la asociación espacial entre los patrones locacionales de dos firmas que compiten en el mismo mercado. Este indicador, llamado índice de asociación espacial, desarrollado por 
Lee (1979), se ha aplicado al análisis espacial de diversos tipos de firmas (Schmidt y Lee, 1979; Lee y Schmidt, 1980), incluyendo las bancarias (Lord y Wright, 1981).

El índice de asociación espacial (IAE) indica si dos conjuntos de unidades comerciales (como sucursales bancarias) pertenecientes a dos firmas en competencia (dos bancos, por ejemplo, Banamex y Banorte) se atraen en el espacio (formando clusters), se rechazan (incrementando la distancia entre ellas) o si su comportamiento de ubicación es independiente entre sí (es decir, si la localización de las sucursales de un banco no está asociada a la ubicación de las sucursales del otro). El IAE se calcula de la siguiente forma:

$$
\mathrm{R}^{*}=\mathrm{d}_{o c} / \mathrm{d}_{e i}
$$

Donde $\mathrm{R}^{*}$ es el índice de asociación espacial, $d_{o c}$ es el promedio de la distancia al vecino más cercano de las unidades de una firma a las unidades de la competencia, y $d_{e i}$ es el promedio de la distancia esperada al vecino más cercano, si los dos grupos de unidades comerciales (como sucursales bancarias) son independientes entre sí. A su vez:

$$
\mathrm{d}_{e i=} \mathrm{n}_{1} /\left(2 \sqrt{p_{2}}\right)+\mathrm{n}_{2} /\left(2 \sqrt{p_{1}}\right)
$$

Donde: $\mathrm{n}_{1} \mathrm{n}_{2}$ son las proporciones de sucursales bancarias respecto al total de sucursales de los dos bancos, mientras que $p_{1} p_{2}$ son las densidades de las unidades comerciales de cada uno de los dos bancos. Si el indicador de asociación espacial es menor a 1.0, indica que existe una tendencia a la atracción espacial entre las sucursales de dos bancos; si es mayor a 1.0, indica una tendencia de rechazo espacial; y si es de 1.0 (o muy cercano a 1.0), indica independencia espacial (Lord y Wright, 1981).

En esta sección se estiman IAE para los bancos más importantes del AMT en 2009: Banamex, Bancomer, Santander, Banorte y HSBC. Estos cinco bancos suman 89 sucursales, que equivalen a $82 \%$ del total en el AMT (cuadro 2).

Lo primero que destaca de los valores de los IAE, y que era de esperarse dados los valores del índice del vecino más cercano, es que existe una clara tendencia a la atracción espacial entre todas las sucursales de los bancos más importantes del AMT: todos los valores son mucho menores a 1.0. ${ }^{15}$ Sin embargo, también es claro que algunos bancos tienden más

\footnotetext{
${ }^{15}$ Todos los indicadores de nivel de significancia son estadísticamente importantes a un nivel de confianza de 95\%. Véase la explicación de la prueba de significancia en Lee (1979), Schmidt y Lee (1979), Lee y Schmidt (1980) y Lord y Wright (1981).
} 


\section{Cuadro 2 \\ Sucursales por banco en el AMT, 2009}

\begin{tabular}{lcc}
\hline \multicolumn{1}{c}{ Banco } & Sucursales & $\%$ \\
\hline Banamex & 22 & 20.2 \\
Bancomer & 19 & 17.4 \\
Banorte & 19 & 17.4 \\
HSBC & 15 & 13.8 \\
Santander & 14 & 12.8 \\
Otros & 20 & 18.3 \\
Total & 109 & 100.0 \\
\hline
\end{tabular}

Fuente: Elaboración propia.

\section{Cuadro 3}

Asociación espacial entre sucursales bancarias en el AMT, 2009

\begin{tabular}{lccccc}
\hline \multicolumn{1}{c}{ Banco } & Banamex & Bancomer & Santander & Banorte & HSBC \\
\hline Banamex & 0 & 0.63 & 0.61 & 0.51 & 0.57 \\
Bancomer & 0.63 & 0 & 0.51 & 0.51 & 0.40 \\
Santander & 0.61 & 0.51 & 0 & 0.36 & 0.52 \\
Banorte & 0.51 & 0.51 & 0.36 & 0 & 0.48 \\
HSBC & 0.57 & 0.40 & 0.52 & 0.48 & 0 \\
Suma & 2.32 & 2.05 & 2.0 & 1.86 & 1.97 \\
\hline
\end{tabular}

Fuente: Elaboración propia.

la aglomeración. Esto se confirma si se revisan las sumas de los IAE para cada banco. Los que más se aglomeran con la competencia son Banorte y HSBC, la suma de los IAE del primero es 1.86 y de 1.97 para el segundo. Por el otro lado, el banco que menos tiende a aglomerarse con la competencia es Banamex (2.32), mientras que Bancomer (2.05) y Santander (2.0) podrían ser calificados como bancos de aglomeración intermedia (cuadro 3).

También está claro que no todos los bancos se atraen de igual manera, algunos se atraen más entre sí y otros menos. Los que registran la máxima fuerza de atracción mutua en el AMT son Banorte y Santander ( IAE = 0.36), seguidos por HSBC y Bancomer $(\mathrm{IAE}=0.40)$. Esto puede tener dos interpretaciones. En una, es posible considerar a Banorte y HSBC los bancos dominantes en el AMT, ya que las sumas de sus IAE (que sintetizan su asociación espacial con todos los demás bancos considerados) son mayores que los de las firmas asociadas espacialmente (Santander y Bancomer). Pero en la otra interpretación, que va en el sentido opuesto a la primera, se diría que Banorte y HSBC podrían ser los bancos que más siguen a los lideres, ya que Bancomer y Santander son los bancos que a escala nacional ocupan el primer y tercer lugar, respectivamente, en términos de su participación de mercado (cuadro 4). A este efecto de asociación espacial con el líder se le llama rational herding effect (que se puede traducir como 


\section{Cuadro 4}

Banca múltiple: participación en el mercado nacional, diciembre de 2008

\begin{tabular}{lcr}
\hline \multicolumn{1}{c}{ Banco } & $\begin{array}{c}\text { Activo total } \\
\text { (millones de pesos) }\end{array}$ & $\%$ \\
\hline BBVA Bancomer & $1,179,244.1$ & 23.86 \\
Banamex & $961,180.7$ & 19.45 \\
Santander & $704,925.5$ & 14.27 \\
Mercantil del Norte & $552,509.0$ & 11.18 \\
HSBC & $468,083.3$ & 9.47 \\
Subtotal & $3,865,942.5$ & 78.2 \\
Otros bancos & $1,075,461.4$ & 21.8 \\
Total & $4,941,403.9$ & 100.0 \\
\hline
\end{tabular}

Fuente: CNBV (2009).

efecto de rebaño racional, Chang et al., 1997). Sin embargo, aunque ahora no contamos con información adicional que nos indique si alguna de las dos interpretaciones es correcta, es suficiente para los propósitos de este trabajo develar lo importante de la asociación espacial entre estas firmas bancarias en competencia.

En el otro extremo estarían las firmas que menos se asocian espacialmente: Banamex-Bancomer ( $\mathrm{IAE}=0.63)$ y Banamex-Santander $(\mathrm{IAE}=0.61)$. Por un lado, esto confirma que Banamex es el banco que genera menos atracción espacial a sus competidores en el AMT; por el otro, llama la atención que estos bancos son los que ocupan las primeras tres posiciones a escala nacional en términos de participación de mercado, lo que puede indicar rechazo espacial a escala intraurbana entre las principales firmas bancarias del país. ${ }^{16}$ Esto parece más claro para Banamex, cuyos IAE con Bancomer y Santander son los más elevados que se registraron en el AMT.

La conclusión que se puede derivar del análisis de asociación espacial entre firmas es que las sucursales bancarias se atraen en el territorio, pero las sucursales de ciertos bancos se atraen todavía más entre sí. Sin embargo, debemos subrayar que con la información disponible no podemos conocer las razones de esta asociación espacial entre firmas específicas.

\section{Accesibilidad: interacción espacial de la oferta y la demanda}

Hasta ahora tenemos las siguientes conclusiones: 1) la oferta de sucursales bancarias en el AMT ha tenido un crecimiento explosivo en los últimos años, acorde con el acelerado aumento de la demanda (población y empleos); 2) los servicios bancarios no se distribuyen de manera homogénea en el Амт, lo que genera un escenario de desigualdad en la provisión de

\footnotetext{
${ }^{16}$ Similar a lo que informan Chung y Kalnins (2001) para el caso de la industria hotelera en Estados Unidos.
} 
los servicios; 3) la estructura espacial de los servicios bancarios en el AMT dejó de ser monocéntrica y pasó a tener una estructura claramente policéntrica; 4) las sucursales bancarias se colocalizan en el territorio, aunque algunas firmas se atraen espacialmente más que otras. Sin embargo, hasta el momento no hemos relacionado la oferta y la demanda, en el marco de una de las variables clave para el diseño tanto de políticas contra la desbancarización y la exclusión financiera, como de la estrategia de ubicación de las firmas bancarias: la accesibilidad. Esto es precisamente lo que se hace en esta sección, para terminar de completar la imagen de la organización espacial de las sucursales bancarias en el AMT.

\subsection{Accesibilidad vs. provisión}

La accesibilidad es tan importante para las sucursales bancarias, que más de $95 \%$ se localiza en las principales vialidades de la ciudad (mapa v). Sin embargo, la tendencia inherente del sector a funcionar en forma de racimo actúa en detrimento de la accesibilidad de gran parte de la demanda potencial.

La accesibilidad a un servicio es muy distinta de la provisión del servicio. Mientras ésta depende principalmente de la magnitud de la oferta, la primera está en función de la localización espacial, tanto de la oferta como de la demanda. Veamos, si se relaciona la extensión del AMT (270 $\mathrm{km}^{2}$ ) con el número de sucursales bancarias, podemos concluir que las 109 sucursales existentes en la ciudad son suficientes para que toda la demanda quede cubierta por, al menos, una sucursal a una distancia máxima de $1 \mathrm{~km} .{ }^{17} \mathrm{El}$ razonamiento es el siguiente: si seguimos la lógica de la teoría de lugar central y cubrimos el AMT con áreas de mercado hexagonales de $2.48 \mathrm{~km}^{2}$ cada una (es decir, con hexágonos de radio igual a $1 \mathrm{~km}$ y con lados de $890 \mathrm{~m}$ ), bastan las 109 sucursales para cubrir el AMT sin dejar a ningún ciudadano a más de $1 \mathrm{~km}$ de alguna sucursal bancaria $\left(2.48 \mathrm{~km}^{2} * 109\right.$ sucursales $=270 \mathrm{~km}^{2}$, que es igual al área de la ciudad). Esto significa que si las sucursales bancarias se distribuyeran homogéneamente en la ciudad, toda la demanda (con condiciones normales de movilidad) del AMT requeriría de entre 10 y medio y 16 minutos para llegar caminando a una sucursal bancaria. ${ }^{18}$

${ }^{17}$ A un kilómetro más treinta metros (1.03 km), para ser exactos.

${ }^{18}$ Las personas del grupo de edad de entre $15 \mathrm{y} 44$ años recorren en promedio $1.6 \mathrm{~m}$ por segundo, mientras que los mayores de 65 ańos recorren en promedio 1.05 metros por segundo. Estos datos se tomaron de la página de Internet del Instituto Forense de Chile: http://forenses.mforos. com/1057458/6543864-tabla-relacion-velocidad-de-peatones-caminando, consultada en abril de 2009. Cabe mencionar que en una encuesta reciente en la ciudad de México, cerca de $92 \%$ de quienes declararon tener cuentas bancarias disponían de una sucursal o de un cajero automático a media hora o menos de su casa (вм, 2005a: 37). 


\section{Mapa V}

Sucursales bancarias y principales vialidades, 2009

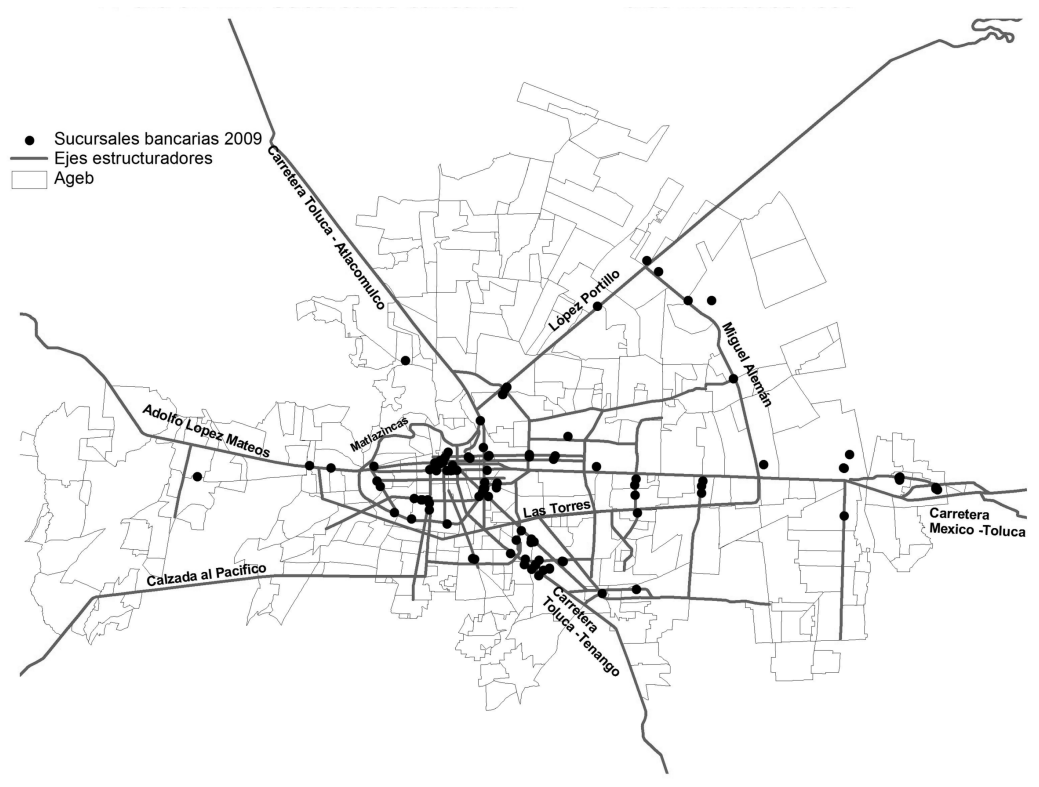

Fuente: Elaboración propia.

Sin embargo, como vimos en las secciones anteriores, las sucursales bancarias no se distribuyen de manera homogénea en el territorio, sino que tienden a aglomerarse en forma de clusters. Por tanto, deben existir diferencias de accesibilidad a los servicios bancarios en la ciudad (como áreas con mayor o menor accesibilidad a servicios bancarios) y la explicación de estas diferencias no se encuentra en la magnitud de la oferta (número de sucursales bancarias), sino en su localización espacial; es decir, en la estrategia de ubicación de los bancos. Cuando se habla de accesibilidad, la variable espacial es lo que marca la diferencia. Por esta razón, los indicadores de provisión (por ejemplo, sucursales bancarias por número de habitantes) dicen poco cuando se analiza la accesibilidad al servicio (como servicios bancarios). Lo que se requiere, entonces, son indicadores de accesibilidad espacial, que permitan estimarla y analizarla.

\subsection{Indice de accesibilidad espacial a servicios bancarios}

El diseño del índice de accesibilidad que se utiliza en este apartado tiene, en general, antecedentes diversos que se reportan en la literatura, ${ }^{19}$ pero responde a los propósitos específicos de este análisis. Como muchos in-

\footnotetext{
${ }^{19}$ En Garrocho y Campos (2006) se hace una amplia revisión de diversos índices de accesibilidad.
} 
dicadores de accesibilidad derivados de la teoría de interacción espacial, combina un elemento de provisión con otro que representa los costos de transporte que enfrenta la demanda para entrar en contacto con la oferta del servicio, más un parámetro que refleja qué tan sensible es la demanda ante los cambios en los costos de transporte. ${ }^{20} \mathrm{Su}$ expresión formal es la siguiente:

$$
I i=\sum_{j}\left(\frac{S j}{O t o t}\right) C i j^{-b}
$$

Dónde $S_{j}$ es la oferta del servicio en la unidad de servicio $j$ (utilizando el número de cajas por cada sucursal bancaria, para distinguir su tamaño); $O_{\text {tot }}$ es la población demandante de servicios bancarios en la zona de estudio (en este caso se utilizó la suma de la población y el empleo en cada Ageb); $C_{i j}$ son los costos de transporte entre el origen $i$ (el centroide de cada Ageb donde se localiza la demanda) y la sucursal bancaria (destino) $j ; \mathrm{y}-\mathrm{b}$ es el parámetro de la fricción de la distancia. ${ }^{21}$

\subsection{Resultados}

El patrón de la accesibilidad en el AMT era claramente monocéntrico en 1990, mientras que en 2009 ya muestra signos inequívocos de policentrismo. En efecto, al inicio del periodo, el CTN de la ciudad registra el pico más alto de accesibilidad (lo cual es lógico ya que concentraba la gran mayoría de las sucursales bancarias del AMT) y a partir de ahí, ésta va decayendo sistemáticamente conforme se incrementa la distancia, perfilando un patrón muy claro de coronas concéntricas de menor accesibilidad (mapa via). Sin embargo, en 2009 el patrón se hace más complejo: se distinguen, al menos, dos zonas no contiguas de alta accesibilidad (el CTN y el subcentro de Metepec-Galerías, al sureste de la ciudad) y una zona con accesibilidad media en el extremo este del AMT, exactamente en la cabecera del municipio de Lerma (mapa vib).

\footnotetext{
${ }^{20}$ Llamado fricción de los costos de transporte o, más generalmente, de fricción de la distancia. Para este trabajo el componente conductual de la fricción de la distancia se estimó igual a -2.0, a partir de lo que reporta la literatura internacional: Morrison y O’Brien (2001) y Hopmans (1986) utilizan este valor para el parámetro. Por su parte, Jones y Simons (1990) mencionan que las actividades de comercio al menudeo usualmente registran parámetros de entre -0.5 y -2.5 . Algunas encuestas sobre servicios bancarios para México parecen confirmar que el parámetro podría ser adecuado (Consulta Mitofsky, 2005).

${ }^{21}$ El índice de accesibilidad está diseñado de manera que es sensible a cambios en: 1) la dimensión de la oferta y la demanda del servicio (Sj y Otot, respectivamente); 2) la relación entre oferta y demanda (Sj/Otot); 3) los costos de transporte entre orígenes y destinos (Cij); 4) la sensibilidad de los usuarios ante cambios en los costos de transporte - b”. En el anexo de Garrocho y Campos (2006) se presenta un ejemplo numérico de este índice.
} 


\section{Mapa VI \\ AMT: superficie de accesibilidad a servicios bancarios, 1990-2009}

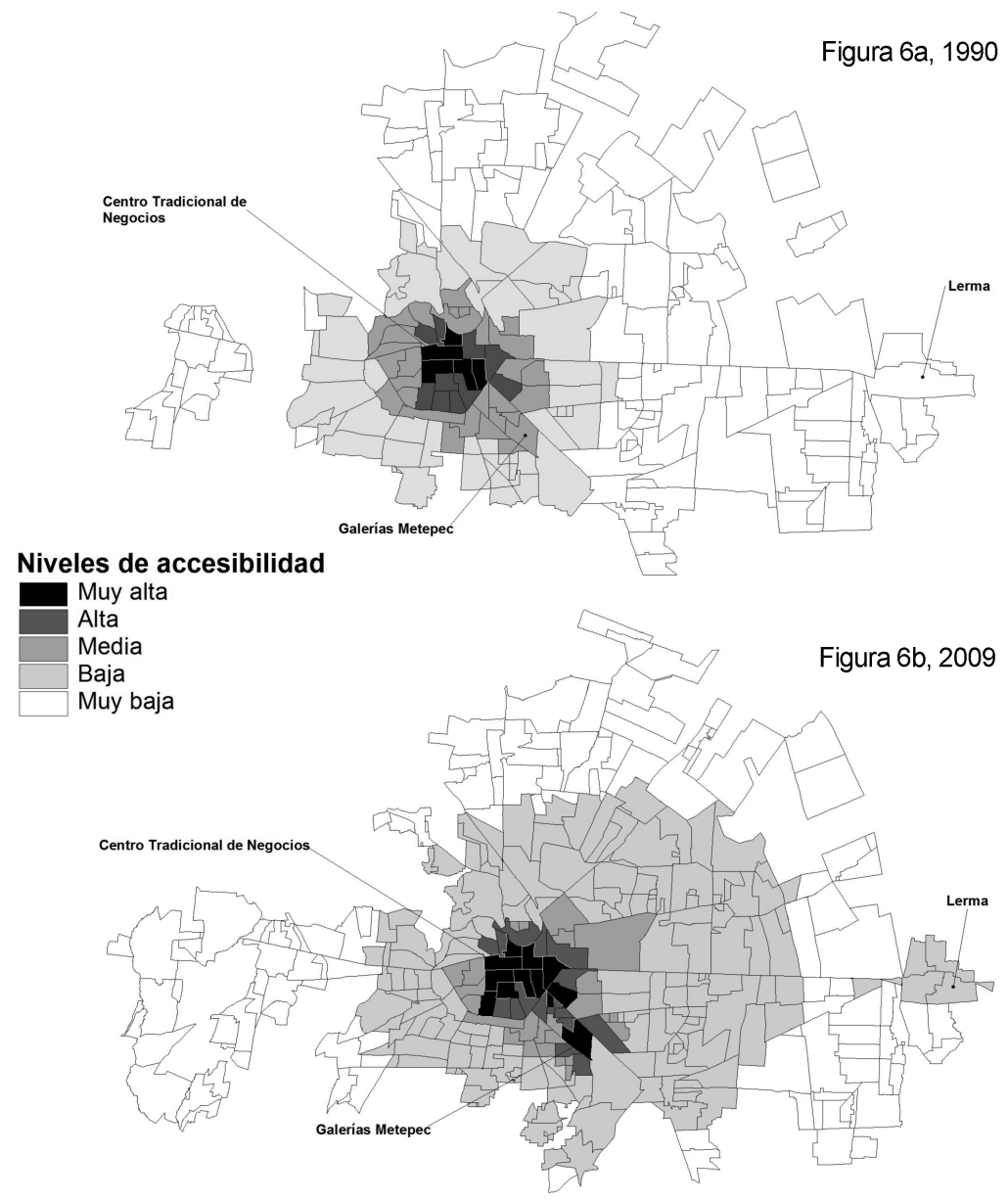

Fuente: Elaboración propia.

Se puede concluir que la accesibilidad a los servicios bancarios disponibles en la ciudad no se distribuye homogéneamente en el territorio, sino que privilegia las zonas más cercanas a los centros de actividad económica más importantes del AMT: el CTN y el subcentro de Galerías-Metepec. Entonces, ¿la estrategia locacional de las sucursales bancarias sigue a la actividad económica (al empleo), sigue a la población (especialmente a la de mayores ingresos) o sigue a ambas? Esto se examina en el siguiente apartado. 


\section{La demanda como determinante de la estrategia locacional: ¿población y/o empleo?}

Para explorar los determinantes de la estrategia locacional de las sucursales bancarias relacionados con la demanda, se realizó un análisis de correlación lineal múltiple. La variable dependiente fue la accesibilidad de cada Ageb a las sucursales bancarias en 2005 (estimada con el índice utilizado en la sección anterior). Este indicador tiene la ventaja que elimina el efecto de frontera que tanto limita a los indicadores de provisión. Veamos, cuando se usa como variable dependiente el número de sucursales localizadas en cada unidad espacial (por ejemplo, Ageb, delegación, municipio) se supone, implícitamente, que las sucursales sólo sirven a la demanda localizada en la misma unidad espacial, lo cual es irreal ya que cualquier persona, sin importar su ubicación, puede utilizar cualquier sucursal bancaria establecida en la ciudad, más allá de la delimitación de las unidades espaciales que se utilicen en el análisis. En cambio, el indicador de accesibilidad supone que las sucursales bancarias funcionan como sistema y que sirven a toda la demanda de la ciudad (no sólo a la que se localiza en cada unidad espacial: Ageb, delegación, municipio), sin importar las fronteras de las unidades espaciales que se estén utilizando, con la ventaja adicional de que incorpora el efecto de fricción de la distancia, ya que supone que la demanda que utiliza el sistema de sucursales bancarias se verá influida por los costos de trasporte (por ejemplo, la demanda preferirá utilizar sucursales más cercanas sobre las más lejanas). Por tanto, mientras los datos de provisión de servicios son espacialmente discretos (se circunscriben a las fronteras de las unidades espaciales consideradas: Ageb, municipios o delegaciones), los de accesibilidad son espacialmente continuos y sus valores permiten delinear una superficie que refleje las variaciones de la accesibilidad en el territorio, lo que expresa con mayor realismo el comportamiento espacial de la demanda.

Por su parte, las variables independientes fueron población (donde vive la gente) y empleo (donde trabajan). Las variables de población se tomaron del Censo de Población 2000 (quienes ganan de dos a cinco salarios mínimos; y los que perciben más de cinco salarios mínimos) y del Conteo de Población 2005 (población total); y las de empleo (que corresponden a 19 de los 20 sectores del scian México: excepto el sector relacionado con actividades del campo, que no es significativo en el AMT) se tomaron de tabulados especiales a escala de Ageb elaborados especialmente por el INEGI para este proyecto, con información del Censo Económico 2004. Una limitación de este análisis se relaciona con las diferencias temporales de las fuentes de información: la variable dependiente (índice de accesibilidad) corresponde a 2005, y las variables independientes corresponden a 
2000 (población por grupos de ingreso), a 2005 (población total) y a 2004 (variables de empleo). Sin embargo, las diferencias en los años de las fuentes de información no son cruciales, si se comparan con la temporalidad de los procesos urbanos. Por tanto, el análisis de correlación múltiple puede mostrar tendencias y aportar información para contestar la pregunta acerca de cuáles son las variables de la demanda más asociadas a la accesibilidad (y por tanto a la localización) a todo el sistema de sucursales bancarias en la ciudad.

\subsection{Método}

Se utilizó el método Stepwise para identificar las variables más asociadas a los cambios en la accesibilidad al sistema de sucursales bancarias. Se calcularon los coeficientes de correlación ( $R^{2}$ ajustada y los coeficientes parciales, tanto estandarizados como no estandarizados, para cada variable seleccionada en el modelo final) y se realizaron las siguientes pruebas para garantizar la significancia de los resultados y prevenir la colinearidad entre las variables independientes: correlaciones entre las variables independientes, análisis de varianza (Anova), pruebas $F$ y t y el cálculo de la tolerancia y los factores de inflación de varianza (VIF) para cada modelo estimado. El paquete estadístico utilizado fue el spss.

\subsection{Resultados e interpretación}

Las variables estadísticamente más asociadas a la accesibilidad al sistema bancario en el AMT son, en orden de importancia: ${ }^{22}$ 1) actividades de gobierno $(0.345)$; 2) población con ingresos superiores a cinco salarios mínimos $(0.339)$; 3) población total $(-0.303)$; 4) otros servicios excepto actividades de gobierno (0.277); y 5) comercio al por menor (0.146). En conjunto, estas variables explicaron 0.625 ( $R^{2}$ ajustada) del comportamiento de la accesibilidad al sistema bancario en la ciudad. La única variable independiente con signo negativo fue la de población total. Esto se explica porque a mayor población total, mayor será también la población de menores ingresos (la correlación parcial o directa entre estas dos variables es de 0.851) y, por tanto, menor el interés de las sucursales bancarias por localizarse en esos mercados espaciales de bajo ingreso. Las demás variables registran signo positivo.

La asociación de la accesibilidad a sucursales bancarias con la presencia de actividades de gobierno, se explica por dos razones principales: 1)

\footnotetext{
${ }^{22}$ El orden de importancia se definió de acuerdo con los valores de los coeficientes beta estandarizados, que coincidió con los coeficientes beta no estandarizados, que son los que se muestran entre paréntesis.
} 
porque las dependencias del sector público son usuarias intensivas de servicios bancarios; y 2) porque gran parte de las dependencias de los gobiernos estatal y municipal se localizan en el centro tradicional de negocios (aglomeradas en torno al palacio de gobierno del estado y a la sede del ayuntamiento, que históricamente se ubican en el centro de las ciudades mexicanas), que también es una zona que ofrece ventajas de localización a las sucursales bancarias para entrar en contacto con el resto de la demanda de la ciudad. Por su parte, la relación de accesibilidad a las sucursales bancarias con la población de mayores ingresos es muy comprensible, porque ésta constituye (junto con el empleo), un segmento de mercado estratégico, por su alta demanda de servicios bancarios.

Las otras dos variables de signo positivo son muy interesantes, porque la explicación de su asociación con la accesibilidad al sistema bancario responde, en gran parte, a las características económicas de la ciudad y a los nuevos patrones de localización del sector comercio al menudeo. Así, la variable Otros servicios excepto actividades de gobierno, muy probablemente resulta significativa porque incluye al subsector Servicios de reparación y mantenimiento, que es una actividad económica muy fuerte en la ciudad (en especial la relacionada con automóviles y camiones, y con equipo y maquinaria agropecuaria, industrial, comercial y de servicios). Por último, la variable Comercio al por menor seguramente se asocia a la accesibilidad a sucursales bancarias, porque incluye el subsector Comercio al por menor en tiendas de autoservicio y departamentales, que no sólo ha tenido un crecimiento muy acelerado en el AMT en años recientes, sino además porque sus nuevas estrategias de organización espacial en la ciudad (en forma de plazas y centros comerciales, por ejemplo) ofrecen opciones de localización muy apreciadas por las sucursales bancarias. ${ }^{23}$ Adicionalmente, este sector incluye diversas actividades del comercio formal que utilizan de forma intensiva los servicios bancarios y requieren ubicaciones muy accesibles a la demanda (que es lo mismo que buscan las sucursales bancarias), como el centro tradicional de negocios y los subcentros terciarios emergentes en la ciudad. ${ }^{24}$

Los resultados del análisis de correlación múltiple confirman algunas de las deducciones derivadas en secciones anteriores: las sucursales bancarias contemplan en el centro de su estrategia locacional la accesibilidad al empleo (en gobierno y en ciertas actividades clave del sector privado) y a la población de más altos ingresos. Por tanto, la respuesta a la pregunta inicial de esta sección, de si las sucursales bancarias seguían al empleo, a la población o a ambas, se debe matizar: las sucursales siguen al empleo

${ }^{23}$ En 2009, 17 sucursales bancarias (16\% del total) se localizaban en plazas comerciales.

${ }^{24}$ Ejemplos de estas actividades son: venta de telas, ropa, calzado, farmacias, farmacias con minisuper, librerías, tiendas de discos, computadoras, decoración, ópticas y joyerías, entre muchas otras. 
(pero más a cierto tipo de empleo) y también siguen a la población (pero específicamente a la de altos ingresos).

\section{Conclusiones}

Si el crecimiento físico, del empleo y de la población del AMT ha sido muy acelerado en los últimos 20 años, el del sistema bancario de la ciudad ha sido aún más dinámico, lo que muestra que el AMT se ha convertido en un espacio de competencia de alta intensidad para las firmas que ofrecen servicios bancarios. Esta competencia, sin embargo, no se ha traducido en una distribución igualitaria de los servicios en el territorio, a pesar de que la estructura espacial del sistema bancario ha dejado de ser monocéntrica para adoptar un patrón policéntrico mucho más complejo y extendido en el espacio intrametropolitano. La explicación de esto no radica en la magnitud del sistema, sino en su estrategia locacional, que se sustenta en tres premisas clave: 1) orientarse a segmentos del mercado específicos (a ciertas actividades en servicios públicos y privados, así como a los grupos de población de mayores ingresos); 2) organizarse en forma de clusters (para aprovechar diversas economías de aglomeración, así como reducir los costos de búsqueda y adquisición de servicios a sus clientes potenciales); y 3) ubicarse en las vialidades más importantes (de preferencia en centros o plazas comerciales). La recombinación de estas tres premisas erige diversas barreras de acceso a los grupos en mayor desventaja, favoreciendo la persistencia de la desbancarización y la exclusión financiera.

En términos de planeación urbana, el tema de la accesibilidad a servicios clave (como los bancarios) comprende tres alternativas básicas orientadas a reducir las barreras de acceso: 1) acercar los destinos a la población (por ejemplo, ubicando las sucursales bancarias más cerca de los grupos en mayor desventaja); 2) facilitar el acceso de la población a los destinos (mejorando el sistema de transporte y vialidades que conectan a los grupos más desfavorecidos con el sistema bancario); y 3) una combinación de las dos estrategias anteriores (como impulsar la creación de subcentros de actividad terciaria, que incluyan servicios bancarios, y nodos de transporte en sitios accesibles a los grupos en mayor desventaja).

Esta última estrategia es la más poderosa. Para el AMT consistiría, fundamentalmente, en una cuidadosa mezcla de acciones interrelacionadas que podrían seguir, en general, la siguiente secuencia: primero, identificar las zonas de bajo ingreso subatendidas por los servicios bancarios y construir o consolidar vialidades importantes que las conecten con el resto de la ciudad; luego, mejorar el servicio de transporte público para agilizar los traslados bidireccionales entre esas zonas de bajo ingreso y el resto del espacio urbano. Posteriormente, se deberían localizar ahí servicios 
públicos de uso intensivo (como hospitales, juzgados, oficinas del registro civil, por mencionar algunos) para atraer flujos importantes de población; y, finalmente, ofrecer incentivos para animar la colocalización de diversas firmas privadas en esas áreas subatendidas. El resultado serían núcleos de servicios públicos y firmas privadas articulados como clusters planificados, donde los servicios públicos jugarían, de inicio, el papel de elementos ancla. Lo más probable es que los clusters generen economías de aglomeración y animen el establecimiento de más firmas (incluidas sucursales bancarias), para producir un efecto autocatalizador favorable a su consolidación.

Por supuesto, los clusters deberían localizarse estratégicamente para maximizar sus beneficios sociales y garantizar su viabilidad económica. Esto no es una utopía. La literatura da ejemplos exitosos sobre nuevas estrategias de localización de grandes empresas comerciales en las periferias pobres de la ciudad de México (Duhau y Giglia, 2007), incluidas firmas bancarias (Solo, 2008). ${ }^{25}$ Estas experiencias se deben analizar, comprender y rescatar.

Sin duda, la agenda de planeación de la accesibilidad a sucursales bancarias es mucho más amplia que los trazos gruesos que aquí se han presentado. Sin embargo, es importante reconocer que se habrá avanzado significativamente cuando se incorporen la variable espacial y la planeación de la accesibilidad a las políticas contra la desbancarización y la exclusión financiera en los espacios intraurbanos. De cualquier manera, cabe mencionar que en esta materia no hay estrategia que haya demostrado ser totalmente eficaz, ni teoría completa que nos brinde las alternativas de planeación que estamos buscando (Connolly y Hajaj, 2001). Así, en tanto logramos una mejor comprensión de la dimensión espacial del sistema bancario, no hay más alternativa que apoyarnos en el conocimiento disponible para elaborar un diagnóstico correcto y actuar en consecuencia, con visión estratégica de largo plazo. Esto implicará ensayar soluciones innovadoras, evaluar resultados, rescatar lecciones e ir aprendiendo en el camino.

\section{Bibliografía}

ABM (Asociación de Banqueros de México) (2009), Anuario financiero de la banca en México, la banca en cifras, http://www.abm.org.mx/ anuario2007/CNBV08.htm; la banca en gráficas, http://www. abm.org.mx/anuario2007/Anexo13.htm, abril de 2009.

\footnotetext{
${ }^{25}$ Por ejemplo, Banco Azteca ha orientado su estrategia de ubicación a espacios intraurbanos de ingreso bajo y alta densidad de población. En 2007 había abierto poco más de 800 sucursales en el país (Solo, 2008), y en 2009 el número ascendía a más 1,400: http://www.bancoazteca.com/PortalBancoAzteca/publica/conocenos/historia/quienes.jsp.
} 
Avery, Robert B. (1991), "Deregulation and the location of financial institution offices", Economic Review, 27 (3), Federal Reserve Bank of Cleveland, Third Quarter, Cleveland, pp. 30-42.

Bernard, Cristina, Lucio Fuentelsaz y Jaime Gómez (2008), "Deregulation and its long-run effects on the availability of banking services in low-income communities", Environment and Planning A, 40 (7), Pion Ltd, Londres, Inglaterra, pp. 1681-1696.

Birkin, Mark, Graham Clarke y Martin Clarke (2002), Retail geography and intelligent network planning, John Wiley and Sons, Sussex, Inglaterra.

BM (Banco Mundial) (2005a), Broadening access to financial services among the urban population: Mexico city's unbanked, vol. 1, Main Report, Banco Mundial, Washington.

Вм (Banco Mundial) (2005b), Brazil access to financial services in urban areas, Banco Mundial, Washington.

вм (Banco Mundial) (2006), Mejorando el acceso a los servicios financieros en México, Programa de Fortalecimiento al Ahorro y Crédito Popular y Microfinanzas Rurales, Project id: P087152, http:// web.worldbank.org/external/projects/main?pagePK=64283627 \&piPK=73230\&theSitePK=40941\&menuPK=228424\&Projec tid=P087152, abril de 2009 .

Buckland, Jerry y Bruce Guenther (2005), "There Are No Banks Here" Financial \& Insurance Exclusion in Winnipeg's North End, Social Sciences and Humanities Research Council of Canada, Winnipeg, http://ius.uwinnipeg.ca/pdf/wira_nobankshere.pdf, abril de 2009.

Caskey, John P. (1992), Bank Representation in Low-Income and Minority Urban Communities, Federal Reserve Bank of Kansas City, Kansas.

CE (Comisión Europea) (2008), Financial services provision and prevention of financial exclusion, Comisión Europea, Bruselas, http://ec.europa.eu/employment_social/spsi/docs/social_inclusion/2008/financial_exclusion_study_en.pdf, abril de 2009. 
Chang, Angela, Shubham Chaudhuri y Jith Jayaratne (1997), Rational herding and the spatial clustering of bank branches: an empirical analysis, Federal Reserve Bank of New York, Nueva York.

Christaller, Walter (1966), Central places in Southern Germany, Prentice Hall, Englewood Cliffs, NJ.

Chung, Wilbur y Arturs Kalnins (2001), "Agglomeration effects and performance: a test of the Texas lodging industry", Strategic Management Journal, 22 (10), John Wiley \& Sons, Inc., West Sussex, Reino Unido (UK), pp. 969-988.

Clark, Phillip J. y Francis C. Evans (1954), "Distance to Nearest Neighbor as a Measure of Spatial Relationships in Populations", Ecology, 35 (4), British Ecological Society, Londres, pp. 445-453.

CNBv (Comisión Nacional Bancaria y de Valores) (2009), http://www. cnbv.gob.mx/default.asp?com_id=0, abril de 2009.

Conapo (Consejo Nacional de Población), "Proyecciones de Población de México 2005-2050", http://www.conapo.gob.mx/00cifras/5. htm, abril de 2009.

Connolly, Chris y Khaldoun Hajaj (2001), Financial services and social exclusión, Financial Services, Consumer Policy Centre-University of New South Wales-Chifley Research Centre, Sydney.

Consulta Mitofsky (2005), Servicios bancarios en México: encuesta nacional en viviendas, México, http://www.consulta.com.mx/interiores/99_pdfs/12_mexicanos_pdf/mxc_NA051006_ServiciosBancarios.pdf, abril de 2009.

Daniels, Peter W. (1985), Service industries: a geographical appraisal, Taylor $\&$ Francis, Londres.

Duhau, Emilio y Ángela Giglia (2007), "Nuevas centralidades y prácticas de consumo en la Ciudad de México: del microcomercio al hipermercado", Revista EURE, XXXIII (98), Santiago de Chile, pp. $77-95$.

Ebdon, David (1991), Statistics in geography, Wiley-Blackwell, Oxford. 
Garrocho, Carlos (2003), "La teoría de interacción espacial como síntesis de las teorías de localización de actividades comerciales y de servicios", Economía, Sociedady Territorio, Iv (14), El Colegio Mexiquense, Toluca, pp. 203-251.

Garrocho, Carlos (2005), "Localización, localización, localización: el manejo del espacio en la competencia entre centros comerciales", Estudios Demográficos y Urbanos, 20 (3), El Colegio de México, México, pp. 449-494.

Garrocho, Carlos (2008), Localización de las firmas terciarias en el espacio intraurbano: un marco teórico-conceptual, El Colegio Mexiquense, Toluca.

Garrocho, Carlos y Juan Campos (2006), “Un indicador de accesibilidad a unidades de servicios clave para ciudades mexicanas: fundamentos, diseño y aplicación", Economía, Sociedad y Territorio, vi (22), El Colegio Mexiquense, Toluca, pp. 349-397.

Garrocho, Carlos y Juan Campos (2009a), "La estructura policéntrica del empleo en el Área Metropolitana de Toluca, 1994-2004", en Guillermo Aguilar (coord.), Periferia urbana, deterioro ambiental y reestructuración metropolitana, Universidad Nacional Autónoma de México, México (en prensa).

Garrocho, Carlos y Juan Campos (2009b), "Estructura espacial del empleo terciario en el Área Metropolitana de Toluca, 1994-2004”, en Gustavo Garza y Luis Jaime Sobrino (coords.), La economia terciaria de México, El Colegio de México, México (en prensa).

Garrocho, Carlos y Zochilt Flores (2009), "Delimitación del centro tradicional de comercio y servicios del Área Metropolitana de Toluca”, Papeles de Población, México, (en prensa).

Garrocho, Carlos, Tania Chávez y Antonio Álvarez (2002), La dimensión espacial de la competencia comercial, El Colegio Mexiquense, Toluca, http://www.cmq.edu.mx/e-book/e-book501289.htm, abril de 2009.

Graves, Steven M. (2003), "Landscapes of predation, landscapes of neglect: a location analysis of payday lenders and banks", The 
Professional Geographer, 55 (3), Association of American Geographers, Washington, pp. 303-317.

Haining Robert (1993), Spatial Data Analysis in the Social and Environmental Sciences, Cambridge University Press, Cambridge.

Hirtle, Beverly y Christopher Metli (2004), “The Evolution of U.S. Bank Branch Networks: Growth, Consolidation, and Strategy, Federal Reserve Bank of New York", Current Issues in Economic and Finance, 10 (8), pp. 1-7, http://www.ny.frb.org/research/current_ issues/ci10-8.pdf, abril 2010.

Hopmans, Anton (1986), "A spatial interaction model for branch bank accounts", European Journal of Operations Research, 27 (2), Elsevier, Londres, pp. 242-250.

Hotelling, Harold (1929), "Stability in competition", Economic Journal, 39, Royal Economic Society, St. Andrews, Escocia, pp. 41-57.

Jones, Ken y Jim Simmons (1990), The retail environment, Routledge, Londres.

Keeble, David y Lilach Nachum (2001), Why do business service firms cluster? Small consultancies, clustering and decentralisation in London and southern England, ESRC Centre for Business ResearchUniversity of Cambridge, Cambridge.

Lee, Yuk (1979), "A nearest-neighbor spatial-association measure for the analysis of firm interdependence", Environment and Planning A, 11 (2), Cambridge, pp. 169-176.

Lee, Yuk y Charles G. Schmidt (1980), "A comparative locacional analysis of a retail activity: the gasoline service station", The Annals of Regional Science, 14 (2), The Annais of Regional Science, Nueva York, pp. 65-76.

Lee, Jay y David W.S. Wong (2001), Statistical analysis with ArcView GIS, Wiley and Sons, Nueva York.

Leyshon, Andrew y Nigel Thrift (1995), "Geographies of Financial Exclusion: Financial Abandonment in Britain and the United States", 
Transactions of the Institute of British Geographers, 20 (3), The Institute of British Geographers, Londres, pp. 312-341.

Lord J. Dennis y David B. Wright (1981), "Competition and spatial location strategy in branch banking: spatial avoidance or clustering", Urban Geography, 2 (3), Bellwether Publishing, Ltd., Birmingham, Alabama, pp. 189-200.

Maoh, Hanna F., Pavlos S. Kanaroglou y Ronald N. Buliung (2005), Modeling the location of firms within an integrated transport and land-use model for Hamilton, Ontario, Centre for Spatial AnalysisMcMaster University, Hamilton, Ontario.

Medina, Carlos y Jairo Núñez (2006), La oferta de servicios del sector fnanciero formal en Bogotá, Centro de Estudios sobre Desarrollo Económico-Universidad de los Andes, http://economia.uniandes. edu.co/es/investigaciones_y_publicaciones/cede/publicaciones/ documentos_cede/2006/la_oferta_de_servicios_del_sector_financiero_formal_en_bogota, abril de 2009.

Morrison, Phillip y Rachel O’Brien (2001), “Bank branch closures in New Zealand: the application of a spatial interaction model, Applied Geography, 21, Elsevier, Londres, pp. 301-330.

Myint, Soe W. (2008), "An exploration of spatial dispersion, pattern and association of socio-economic functional units in an urban system", Applied Geography, 28 (3), Elsevier, Londres, pp. 168-188.

O’Sullivan, Arthur (2007), Urban economics, McGraw-Hill, Boston.

Parr, John B. (2002), "Agglomeration economies: ambiguities and confusion", Environment and Planning A, 34, Universidad de Cambridge, Cambridge, pp. 717-731.

Porter, Michael y Orjan Solvell (1999), "The role of geography in the process of innovation and the sustainable competitive advantage of firms", en Alfred D. Chandler, Peter Hagstrom y Orjan Solvell (eds.), The Dynamic Firm: The Role of Technology, Strategy, Organization, and Regions, Oxford University Press, Oxford.

Rojas Suárez, Liliana (2006), El acceso a los servicios bancarios en América Latina: identificación de obstáculos y recomendaciones, Center for 
Global Development, Washington, http://www.cgdev.org/content/publications/detail/13932, abril de 2009.

Ruiz Durán, Clemente (2004), "Los desbancarizados: el problema de los mercados financieros segmentados", Comercio Exterior, 54 (7), México, pp. 566-574.

Ruiz Durán, Clemente (2005), "Restricciones de acceso al sistema financiero en el área metropolitana de la Ciudad de México y la necesidad de fuentes alternas de financiamiento", ponencia presentada en Encuentro 2005: año internacional del microcrédito, México.

Schmidt, Charles G. y Yuk Lee (1979), "An intrametropolitan analysis of retail location patterns and competitive processes", The Social Science Journal, 16, Western Social Science Association-Elsevier, Londres, pp. 43-52.

Solo, Tova María (2008), "Financial exclusion in Latin America or the social costs of not banking the urban poor", Environment and Urbanization, 20 (1), Sage-International Institute for Environment and Development, Londres, pp. 47-66.

TFrbC (The Federal Reserve Bank of Chicago) (2001), Chicago Fed Letter, 162, TFRBC, Chicago.

Topçu, E. Ümran (2001), "Spatial distribution of banks in Istanbul”, ponencia presentada en el 41 Congreso de la European Regional Science Association, Zagreb (Croacia), 29 de agosto-1 de septiembre, http://www-sre.wu-wien.ac.at/ersa/ersaconfs/ersa01/ papers/full/222.pdf, abril de 2009.

Willer, David, J. (1990), A spatial decision support system for bank location: a case study, National Center for Geographic Information and Analysis-State University of New York at Buffalo, Buffalo-Nueva York.

Recibido: 19 de mayo de 2009. Aceptado: 12 de octubre de 2009. 
Carlos Félix Garrocho-Rangel. Investigador nacional nivel Ir. Profesorinvestigador de El Colegio Mexiquense desde 1986. Maestro en desarrollo urbano (El Colegio de México, 1987) y doctor en geografía social (Universidad de Exeter, Inglaterra, 1992). Investigador asociado en el departamento de geografía de la Universidad de Glasgow (Escocia, 1988) y egresado del Programa para Ejecutivos y/o Directores en Administración de Calidad (The Association for Overseas Technical Scholarship, TokioYokohama, Japón, 2002). Secretario de Planeación del Desarrollo del Gobierno del Estado de San Luis Potosí de 1997 a 2003. Actualmente realiza investigación sobre la estructura policéntrica del área metropolitana de Toluca y sobre la organización espacial de su sistema comercial y de servicios.

Juan Campos-Alanís. Licenciado en planeación urbana (Universidad Autónoma del Estado de México, 1996), maestro en desarrollo regional (Instituto Mora, 2001), estudios de doctorado en geografía (UNAM). Profesor de tiempo completo en la Facultad de Geografía de la Universidad Autónoma del Estado de México desde 2003 en el área de geografía económica. Actualmente realiza investigación sobre la estructura policéntrica del área metropolitana de Toluca, sobre la organización espacial de su sistema comercial y de servicios y sobre marginación y pobreza en el Estado de México. 